Portland State University

PDXScholar

3-15-1995

\title{
An Exploration of the Value of Future TESOL Teachers Reflecting on their Pasts as Language Learners
}

Sarah Elizabeth Lawrence

Portland State University

Follow this and additional works at: https://pdxscholar.library.pdx.edu/open_access_etds

Part of the Bilingual, Multilingual, and Multicultural Education Commons Let us know how access to this document benefits you.

Recommended Citation

Lawrence, Sarah Elizabeth, "An Exploration of the Value of Future TESOL Teachers Reflecting on their Pasts as Language Learners" (1995). Dissertations and Theses. Paper 4946.

https://doi.org/10.15760/etd.6822

This Thesis is brought to you for free and open access. It has been accepted for inclusion in Dissertations and Theses by an authorized administrator of PDXScholar. Please contact us if we can make this document more accessible: pdxscholar@pdx.edu. 


\section{THESIS APPROVAL}

The abstract and thesis of Sarah Elizabeth Lawrence for the Master of Arts in TESOL were presented March 15, 1995, and accepted by the thesis committee and the department.

COMMITTEE APPROVALS:

Kimberley Brown, Chair

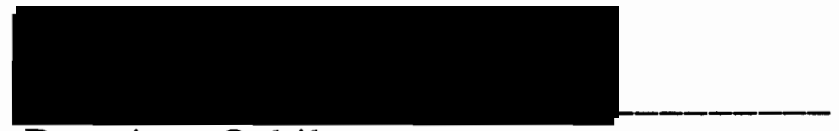

Beatrice Oshika

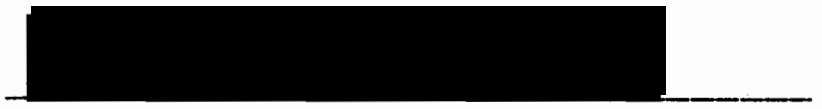

M. Carrol Tama

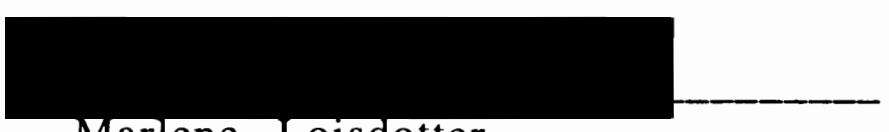

Marlene Loisdotter

DEPARTMENT APPROVAL:
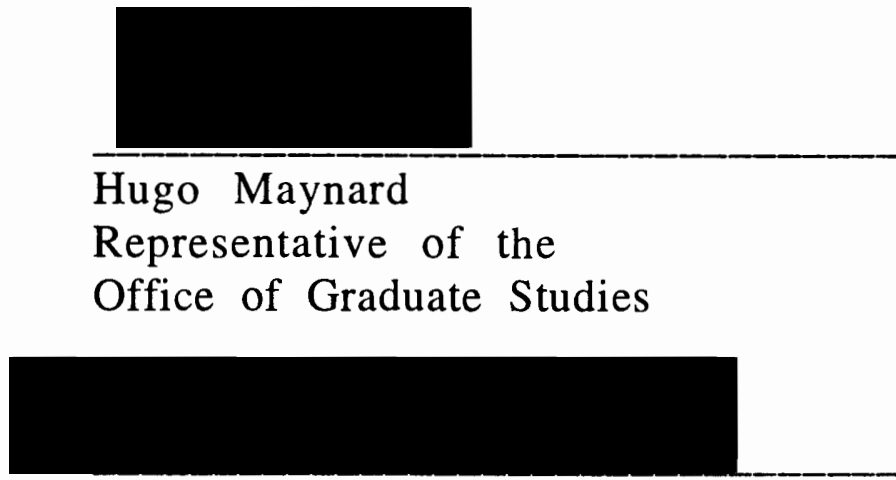

Beatrice Oshika, Chair

Department of Applied Linguistics

******************************************************************************

ACCEPTED FOR PORTLAND STATE UNIVERSITY BY THE LIBRARY

by

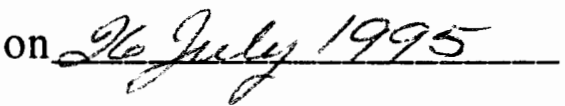




\section{ABSTRACT}

An abstract of the thesis of Sarah Elizabeth Lawrence for the Master of Arts in TESOL presented on March 15, 1995.

Title: An Exploration of the Value of Future TESOL Teachers Reflecting on their Pasts as Language Learners

Virtually all future teachers of ESL/EFL have been foreign- or second-language learners themselves. However, reflection on their own past language-learning experiences is usually not integrated into the coursework of professional TESOL preparation programs and there has been little published research in TESOL in which students in professional TESOL preparation programs reflect on their past language learning experiences. The purpose of this research was to explore the effects on TESOL Methods students of revisiting a past language-learning experience.

The subjects were students in a TESOL Methods class. This study examined an assignment given to these students to write a short "language learning narrative" (LLN) describing a past languagelearning experience. The data base of this qualitative study included 
included thirty-one LLNs, thirty-one free-writes and eleven interviews with these TESOL students.

The results indicate that the students' memories of affective factors such as nervousness about speaking in class and feeling successful or unsuccessful as language learners were prominent in their minds, as was a strong focus on the teacher. The benefits to the TESOL students of writing the LLNs included increased sensitivity to the perspective of the learner, willingness to engage in reflection, and an understanding of the connections between their past experiences and the kinds of experiences they wanted to create in future language classrooms. While the TESOL students seemed to have mastered the latter skill, they did not see their past language learning experiences as a resource that could give them insights into particular teaching dilemmas. Also, they tended to make direct generalizations based on their own past reactions as language learners to what they imagined their future students' reactions would be. They wanted to recreate for their future students experiences that had been positive for them and do the opposite of what the teachers of language classes they had experienced as negative had done.

The study concludes that the LLN assignment is recommended for use in other professional TESOL training programs, with modifications that would encourage the students to become aware of variations in learner preferences and to view their past language learning experiences as a continuing resource. 


\title{
AN EXPLORATION OF THE VALUE OF FUTURE TESOL TEACHERS REFLECTING ON THEIR PASTS AS LANGUAGE LEARNERS
}

\section{b y}

\section{SARAH ELIZABETH LAWRENCE}

A thesis submitted in partial fulfillment of the requirements for the degree of

\author{
MASTER OF ARTS \\ in \\ TESOL
}

\author{
Portland State University \\ 1995
}




\section{ACKNOWLEDGEMENTS}

As I was going through my old assignments from the MA:TESOL program the other day in preparation for my move to Japan, I found my own language learning narrative from October 1992. I had written about a high school French class in which $I$ had felt a sense of belonging. Marge Terdal had written in the margin, "I hope you'll get that same sense of belonging in our TESOL program." I truly have, and my two and a half years in Portland studying at PSU have been among the happiest in my life.

Thanks to all the professors in the Department of Applied Linguistics, who make an extraordinary effort to give of their time outside of class to help students and to get to know us. Several in particular have helped me to believe in myself by showing interest in my ideas and giving me opportunities to practice various aspects of being a professional language educator. Thanks to Marge for the opportunity to be your teaching assistant for a term and for all your volumes of interest and encouragement. Thanks to Jan DeCarrico for inviting me to present my work on pragmatic devices in the OCA video (doing that presentation meant a huge step forward for me) and for all the laughter. Thanks to Kim Brown for planting the seed in my head that I could try different ways of working and of talking about myself.

I'm grateful to everyone who contributed to the thesis process. Thanks, Kim, for agreeing to work with me as my thesis advisor 
against a rather tight deadline. Thanks to Carrol Tama for the consultations. Marlene Loisdotter, it has truly been a pleasure to know you. Thanks to the rest of the committee, to my friends and family, and last but not least, to Rosie, who was always there.

Just as Marge wished for me when I began the program, I have enjoyed being part of the PSU TESOL community. My thanks to this community would not be complete without mentioning my classmates and friends, especially my wonderful best friends Cheryl Hill, Angela Zagarella-Chodosh, Nariyo Kono, Akiko Fukumura, and Vivian Lu. You are all wise and strong women, plus being lots of fun! I'll also always remember the great study group with Angela, Cheryl, Elena Cavanaugh, and Larry Wilcock that lasted through several courses and brought unsurpassed hilarity to the study of applied linguistics.

As I prepare to leave Portland in a few days to begin my teaching position in Tokyo, I know that $I$ will always remain a proud graduate of PSU and forever hold fond memories of my time here. 


\section{TABLE OF CONTENTS}

PAGE

ACKNOWLEDGEMENTS $\ldots \ldots \ldots \ldots \ldots \ldots \ldots \ldots \ldots \ldots \ldots$ v

LIST OF TABLES $\ldots \ldots \ldots \ldots \ldots \ldots \ldots \ldots \ldots \ldots \ldots \ldots \ldots \ldots \ldots \ldots$

\section{CHAPTER}

I INTRODUCTION $\ldots \ldots \ldots \ldots \ldots \ldots \ldots \ldots \ldots$

I I REVIEW OF THE LITERATURE $\ldots \ldots \ldots \ldots \ldots \ldots 7$

Introduction $\ldots \ldots \ldots \ldots \ldots \ldots \ldots$

Reflective Teaching $\ldots \ldots \ldots \ldots \ldots$

Narrative Inquiry $\ldots \ldots \ldots \ldots \ldots \ldots \ldots$

Journal Writing $\ldots \ldots \ldots \ldots \ldots \ldots \ldots \ldots \ldots \ldots \ldots \ldots$

II I METHODOLOGY .................. 31

Research Design ............... 31

Setting and Subjects ............ 31

Approach ................. 32

Data Collection and Analysis Procedures ..... 37

Language Learning Narratives . . . . . . . 37

Free-writes $\ldots \ldots \ldots \ldots \ldots \ldots \ldots \ldots 40$

Guided Interviews $\ldots \ldots \ldots \ldots \ldots \ldots \ldots 4$ 


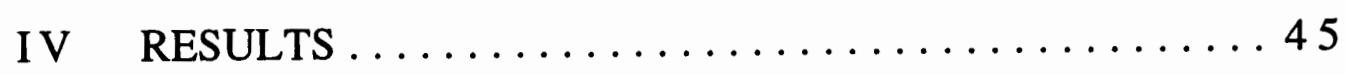

Language Learning Narratives ......... 45

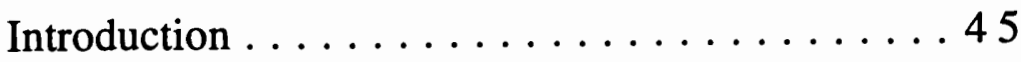

Characteristics of Teachers

who were Liked ............. 50

Characteristics of Teachers

who were Disliked ............. 53

Students' Nervousness about Speaking . . . . 56

Students' Emotional Responses to

Language Learning Experiences . . . . . . . . 59

Students' Language Learning Strategies . . . . 65

Teachers' Approaches to

Language Teaching .............6 69

In-Class Free-writes $\ldots \ldots \ldots \ldots \ldots \ldots$

Introduction $\ldots \ldots \ldots \ldots \ldots \ldots 7$

Emotional Experiences . . . . . . . . 76

First Guiding Question .......... 78

Second Guiding Question ...........8 80

Third Guiding Question ........... 90

Interviews $\ldots \ldots \ldots \ldots \ldots \ldots \ldots$

Introduction $\ldots \ldots \ldots \ldots \ldots \ldots$

First Question ............... 93

Second Question . . . . . . . . . . . . 99 
Third Question ................ 104

Fourth Question ................ 111

V CONCLUSION .................... 117

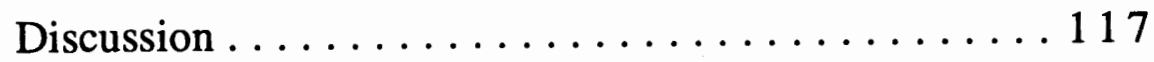

Introduction . . . . . . . . . . . . 117

First Guiding Question ........... 117

Second Guiding Question ............ 119

Third Guiding Question . . . . . . . . . 133

Limitations of the Study and

Suggestions for Further Research . . . . . . . . 134

Implications for TESOL Teacher Education . . . . . 138

\section{APPENDIX}

A CHARACTERISTICS OF EACH NARRATIVE ....... 148 


\section{LIST OF TABLES}

TABLE

PAGE

I First Languages (L1s) and Languages

Being Learned (L2s) . . . . . . . . . . . . 47

I I Other Characteristics of each Narrative . . . . . 47

III Number of Narratives Mentioning each Theme . . . . 51

IV Number of Free-writes Mentioning each Theme . . . 82

$\mathrm{V} \quad$ Answers to First Interview Question ......... 95

VI Answers to Second Interview Question ......... 101

VII Answers to Third Interview Question .......... 106

VIII Answers to Fourth Interview Question .......... 113 


\section{CHAPTER I}

\section{INTRODUCTION}

Virtually all future teachers of English as a Second Language (ESL) and English as a Foreign Language (EFL) have been foreign- or second-language learners themselves at some point. Native speakers of English who decide to become professional Teachers of English to Speakers of Other Languages (TESOL) have almost all studied another language, in many cases reflecting the typical interest of people who choose this field in learning about and visiting different cultures. Others have studied another language because it was a general education requirement in high school or college, including the requirement of most M.A.-TESOL programs that candidates demonstrate proficiency in another language. The languages studied by students in TESOL preparation programs range from the traditional Romance languages and German to languages such as Japanese, Hebrew and Swahili. Some have studied the foreign language in the United States, and others in a country where it is spoken. Non-native speakers of English who enter TESOL preparation programs have studied EFL themselves in their native countries, and often ESL in the United States as well, before beginning regular TESOL coursework.

These future teachers enrolled in TESOL preparation programs probably recall their past language-learning experiences with 
varying degrees of clarity and frequency. Some may consciously compare their own practice teaching with the teaching style of their favorite foreign-language teacher from the past. Others may occasionally recall their own feelings of pride or frustration as language learners in conversations with other students in the TESOL program. Still others may feel their experience was too long ago to remember well. In any case, referring back to one's experience as a language learner is usually done alone or among friends, rather than being integrated into the TESOL preparation program. Although the memories exist in varying degrees of consciousness, with some effort, all TESOL students could probably remember more details of their past experiences than they would have believed they could. What place might coursework involving deliberate, thoughtful revisitation of one's past as a second- or foreign-language learner have within professional TESOL preparation programs?

There has been little published research in TESOL in which future teachers reflect on their past language learning experiences. This does appear to be an emerging area of interest, however. Leaders in language education are beginning to focus on teacher reflection (Bartlett, 1990; Richards \& Lockhart, 1994; Wallace, 1991; Freeman \& Richards, 1993). In addition, some researchers are beginning to look at links between learning styles and language learning experiences (Rebecca Oxford, Colette Green, John Green, scheduled presentation at TESOL 1995 Conference, "When Students Write their Language Learning Histories"). The attention being given to teacher reflection by language educators is part of the reflective 
teaching movement in general. According to Schon (1983), the reflective teaching movement involves helping preservice and inservice teachers learn to value the kind of knowledge which is non-technical but instead draws on reflection, critical thinking, and experience. He says these are skills necessary for "making sense of uncertainty, performing artistically, setting problems, and choosing among competing paradigms ..." (p. 20). Reflective teaching encourages teachers to recognize and draw upon their inner resources of reflectivity in addition to looking to theories and research as the "experts" on language teaching.

There are several main themes in reflective education: the integration of theory and practice (Schon, 1983; Greene, 1986; Millies, 1992); increasing focus on the perceptions, intentions, and life history of the teacher as a whole person rather than simply the implementer of curricula and methodologies (Schon, 1983; Smyth, 1989; Schubert, 1991); valuing of personal experience (Schon, 1983; Schubert, 1991; Smyth, 1989; MacKinnon, 1992); and teacher empowerment (Smyth, 1989; Greene, 1986).

The focus on reflection, in addition to being advocated for practicing teachers, has spread to teacher education programs (Porter, Goldstein, Leatherman, \& Conrad, 1990; Schon, 1983; Greene, 1986; Holly, 1989; Smyth, 1989; Canning, 1991; Clandinin, 1992;

Richert, 1992). Most of the reflective assignments (usually dialogue journals) given to future teachers involve reflecting either on their practice teaching (Porter, Goldstein, Leatherman, \& Conrad, 1990; Clandinin, 1992; Richert, 1992) or on course material (readings, 
lectures, films, discussions, etc.) (Porter, Goldstein, Leatherman, \& Conrad, 1990; Richert, 1992). The preservice teachers' past experiences as learners, whether of foreign languages or other subjects, are not used as a topic for reflection.

However, research on teacher education programs suggests that such reflection on past learning experiences may be helpful. Research indicates that preservice and novice teachers go through a developmental stage during which their attention is turned inward on themselves (Holly, 1989; Kagan, 1992; Richert, 1992). During this stage, their reflections focus on their own feelings and behaviors until their image of self as teacher is resolved. Only then can they move on to focus on and analyze their teaching.

Research also shows that teachers are strongly influenced by their past experiences as learners (Carr, 1989; Clandinin, 1989; Cole, 1990; Kagan, 1992; Mantle-Bromley, 1992). Kagan's study of forty teacher education programs found that preservice teachers enter the programs with personal beliefs about teaching and images of themselves as teachers, both of which usually remain inflexible throughout the program, regardless of new information. These ideas were developed during their past experiences as learners. Kagan also found that, because of their past experiences with school, students in teacher education programs tend to assume that their students will have learning styles and interests like their own.

Kagan (1992) sees a connection between these two areas of findings (the attention-inward period and the strong influence of past experiences as learners). She believes the success of the 
attention-inward period depends on the teachers-in-training becoming open to change. She says this period should not simply be tolerated, but rather used to full advantage by leading students to explore their past experiences with education, because in order to be open to changing through the assimilation of new information, students must first be conscious of what their present beliefs are and how the past has influenced them.

In the case of negative past experiences as learners, there may be an additional benefit to that of becoming more open to change. There is a general consensus in the field of psychology that peoples' past experiences can have an impact on their psychological health. When negative experiences (provided they are not severely traumatic ones) are suppressed, they can be associated with longterm stress and disease, but actively confronting and coming to terms with upsetting experiences can be cathartic (Pennebaker, 1988).

Given the above findings, the purpose of this research is to explore, through studying in depth one assignment given to students in a TESOL preparation program, the effects on the students of revisiting a past foreign- or second-language learning experience. To date, a body of literature on what happens when future language teachers reflect on their own language-learning experiences has not been available. The assignment the research focuses on was given to students in a state university TESOL Methods class. It is called a "language learning narrative" (LLN). The assignment is a two- to four-page descriptive paper in which the students recall a past 
language-learning experience, whether in a classroom or in a naturalistic setting, positive or negative. The data for the study consist of the narratives, subsequent in-class free-writes about the experience of writing the narratives, and interviews. The method used is qualitative and data-driven. Qualitative methods are well suited for research that is exploratory, involves peoples' subjective experience, and relies on naturalistic data. The guiding questions for the study are the following, although additional questions arose as the study progressed.

1. What happened when the subjects wrote the LLNs?

a. What did they write about?

b. What was the experience of writing the LLNs like for the subjects?

2. Was it helpful to the subjects to have revisited their pasts as language learners through the LLNs? If so, how?

3. Did the different categories of experiences bring particular kinds of benefits? 


\section{CHAPTER II}

\section{REVIEW OF THE LITERATURE}

\section{Introduction}

This study fits within the tradition of reflective teaching because of the focus on individuals reflecting on their own experience. There are several recurring themes in reflective education: the integration of theory and practice (Schon, 1983; Greene, 1986; Millies, 1992); increasing focus on the perceptions, intentions, and life history of the teacher as a whole person rather than simply the implementer of curricula and methodologies (Schon, 1983; Smyth, 1989; Schubert, 1991); valuing of personal experience (Schon, 1983; Schubert, 1991; Smyth, 1989; MacKinnon, 1992); and teacher empowerment (Smyth, 1989; Greene, 1986). As these themes are elaborated in the review, their relevance to the topic of future English as a second language (ESL) and English as a foreign language (EFL) teachers examining their past experiences as language learners will emerge. This review begins with the field of reflective teaching, then discusses narrative inquiry as a research method within the field. The review ends with a presentation of research on journal writing since this genre of personal writing has many similarities with the language learning narrative (LLN) assignment. 
Reflective Teaching

Reflective teaching has its roots in the thought of the wellknown philosopher of progressive education, John Dewey (18591952). During the decades Dewey was writing on his ideas about experience and reflection in education, the prevailing practice was for students to passively receive and often memorize information that had been prepared for them by teachers and textbooks. Dewey argued that this is not the way learning takes place and also that the classroom alone is too limited a sphere for learning.

Dewey believed that people learn about the world through experience. He defined the educational process as "a continual reorganization, reconstruction and transformation of experience" (1916, p. 50). He said educational growth consists of combining past experiences with present experiences in order to be better able to understand future experiences (Deighton, 1971). This is why he argued against new information being presented to children in an isolated way rather than connections being built between the new information and something the children already know, and advocated teaching methods that addressed the everyday experience of the child. Dewey believed that educational experiences occur when we make a connection in our minds between what we do to things and what happens to them or us in consequence. For example, if children burn themselves on a candle, it is only an educational experience if they realize the connection between the pain and the candle and are able to generalize that the same thing would happen again in similar circumstances. 
This was in contrast to the prevailing practice at the time of information being given to students. Dewey asserted that if people learn things through experience and not through receiving and memorizing information from an outside source, the learning is personally meaningful and more likely to be remembered. So it is this natural form of learning from experience, by doing and then reflecting on what happened, which Dewey made central in his experientialist philosophy. He defined reflection as a state of doubt or hesitation which initiates thinking, and an act of inquiring to find information that will resolve the doubt (MacKinnon, 1992). Dewey planted the seeds for the concept of reflective practice for teachers when he advocated that they also employ the above kind of learning for themselves in their practice, through making connections and generalizations from events that occur in their daily experience.

Today, researchers in reflective teaching look toward Donald Schon's pioneering work, The Reflective Practitioner (1983), which draws on Dewey's philosophy. Following publication of this work, interest and writing on reflective teaching proliferated. Studying several different professions including teaching, Schon built on Dewey's notion that inquiry in practice is the basis for the development of professional knowledge. Schon added the concept that professionals have their own tacit "theories" that can be discovered by carefully examining their actions. Often the practitioners are not fully aware of what these are, but they exist nonetheless. Thus, practitioners' actions should not be considered to be random or judged as failing to match up to theories imposed from 
the outside, but rather, those who observe should "give practitioners reason," that is, assume that underlying personal theories and meanings exist and simply need to be discovered (Schon, 1983, 1987; MacKinnon \& Erickson, 1992).

Also, whereas Dewey speaks of teachers deliberating about their practice, especially in response to problems, Schon (1983) develops the concept of construction of a practice: teachers build their practice from "frames" that come from their individual past experience. Teachers build up their personal theories based on the way they understand their own past experiences and present knowledge. This is different from Dewey's thought in that Dewey advocated that teachers form their practice based on "foundations of education" (theories from fields such as education and psychology). Schon agrees that teachers should be knowledgeable of findings from these fields, but contends that, since personal experience is the main ingredient in constructing teachers' personal theories of teaching, teacher education programs should use prospective teachers' past educational experiences as building blocks for new information and experiences in the program, and provide opportunities to practice "reflection-in-action" in teaching situations (MacKinnon \& Erickson, 1992)

Schon (1983) discusses the political climate in which teaching is situated today and says that attention has been turned to the quality of teaching in an effort to improve results quantifiably and thus, according to conservative policy-makers, to address some of society's ills through education. Schon refers to this as "the crisis in 
confidence in professional knowledge" (p. 20) and says that "technical rationality," the making of classroom decisions based only on the application of outside theory and not making use of the teacher's resources as a whole person, such as experience, intuition, and emotion, is not sufficient for successful teaching, which includes "making sense of uncertainty, performing artistically, setting problems, and choosing among competing paradigms" (p. 20).

This idea that teachers require more than technical knowledge to deal with complex, changing teaching situations is the cornerstone of reflective teaching, laid down by Dewey and Schon. The four themes presented earlier, attention on the whole person who teaches, valuing of personal experience, integrity of theory and practice, and teacher empowerment, combine to indicate what is needed in order to create a supportive atmosphere within which teachers can reflect on their practice. In the years since the publication of The Reflective Practitioner (1983), numerous theorists and researchers have built up the field of reflective teaching by adding their ideas along the lines of these themes.

The trend toward attention being increasingly focused on the teacher as a multi-faceted person began with Dewey and Schon. Dewey's writings began to suggest a wider role for the teacher than simply dispenser of knowledge: since he saw learning as originating in experience, he believed that teachers should reflect on their practice and that these reflections had to take into account the teacher as an individual, with unique perspectives and experiences. Greene (1986) places emphasis on the personal development of 
teachers since classroom life is situation-specific and their responses to what happens in the classroom will need to rely on intuition, awareness and emotions together with theory and training.

An example of research that focuses on the teacher as a whole person whose inner life and life outside of school are of interest in understanding classroom phenomena is Millies' (1992) study of a veteran high school English teacher. In interviews with the teacher, "Alice," Millies examined the relationships between the teacher's life and three areas of teaching: personality, assumptions, and repertoire. She found connections between the teacher's identity and values, and the curriculum: for example, Alice's personal value of family could be seen in the nurturing classroom environment she established.

In addition to representing a new focus on who the person is who teaches, studies of teachers' lives such as Millies' (1992) also demonstrate a valuing of teachers' personal experience. This has grown out of Dewey's experiential philosophy -- his belief that learning comes from experiences in the world -- and Schon's (1983) assertion that teachers' personal theories derive from their own life experiences. Smyth (1989) also believes that teachers' current practices are informed by their past experiences, and advocates that teachers be aware of their past experiences in order to better understand the origins of their own particular teaching practices. Smyth also maintains that a teacher's conscious reflection is a demonstration of belief in the validity of the experiential and intuitive knowledge of the practitioner in the face of the 
conservative "back to basics" movement which promotes techniques and formulas being handed down to teachers.

Schubert (1991) adds that teacher experience is also a collective phenomenon which should be studied and developed into a body of literature analogous to the way traditional theories of teaching have been. Traditionally, what and how teachers learn from experience has gone unwritten but Schubert argues that it should be a genuine area of inquiry so that the insights from teacher experience will not continue to be lost from generation to generation. $\mathrm{He}$ refers to this desired body of information on teacher experience as "teacher lore," which he characterizes as:

the study of the knowledge, ideas, perspectives, and understandings of teachers ... inquiry into the beliefs, values, and images that guide teachers' work ... an attempt to learn what teachers learn from their experience. (p. 207)

A third theme in reflective teaching is the desired greater integration of theory and practice. Schon (1983) believes that inquiry in practice is the basis for the development of professional knowledge, as opposed to a rigid separation of research and teaching, with practitioners' only role vis-a-vis research being to apply theory developed by other people outside of the classroom situation, to their classrooms. Schon also speaks of teachers having their own tacit, personal theories which can be discovered through examination of their teaching. Schubert (1991) addresses this concept in his coining of the term "praxis" to mean:

the blend of theory ((teachers') evolving ideas and personal belief systems) and practice (their reflective action). (p. 207) 
Smyth (1989) echoes Schon's opposition to rigid separation of theory and practice; asserting that the separation of thought from action is analogous to the division between mental and manual labor. MacKinnon (1992) also says that theory from formal academic disciplines should not be handed down to teachers as if it were the only valued source of knowledge. Greene quotes Dewey:

(Teachers should) seek for freedom in something which comes to be, in a certain kind of growth; in consequences rather than antecedents. (Greene, 1986, p. 76)

Greene interprets the quote to mean that the mindless application of outside theory to one's own practice ends in that present application whereas reflective inquiry points to future possibilities as well.

A fourth general theme of reflective teaching is that of teacher empowerment. Although Schon does not refer explicitly to empowerment, it is inherent in his thought: his concept of constructing one's own practice is empowering to teachers in the sense that they are seen as having expertise coming from within them as opposed to the paradigm of teachers merely applying external theory to their practice. Smyth (1989) sees teacher empowerment as a result of reflection since teacher reflection is occurring within the context of the current educational political climate, in which conservative educational reformers are promoting certain prescribed techniques and actions teachers should take. The formulaic nature of these techniques and actions deemphasizes the importance of the teacher as a unique human being. According to Smyth, the conservative educational reformers' purpose for wanting to reform education is to make it more responsive to the economic 
needs of society, in other words, to improve students' skills in measurable ways rather than to empower them to be self-sufficient through education. So, teacher reflection is empowering to teachers because it entails the acting out of beliefs and values that run counter to those of technologically-minded reformers. Teachers' reflection, therefore, is empowering in its questioning of the purpose of education.

Greene (1986) also speaks of the "lulling atmosphere" of the back-to-basics movement and says that teachers' main task is not simply to accept the pressure of this atmosphere by teaching only skills that can be measured but to empower people to imagine beyond themselves to create life goals, and to think critically and use their intuition and emotion to interpret life's events. According to Greene, only teachers who are themselves self-aware because of their own reflection are able to allow their students the space and the examples they need to develop in these ways.

Along with reflective teaching theory, research approaches to studying teacher reflection are also being developed. Mohlman Sparks-Langer \& Colton (1991) summarize three of these approaches. The cognitive approach deals with how teachers use knowledge in planning and decision making and how the knowledge is organized, that is, schema theory. The critical thinking approach stresses values and goals and as well as social and ethical issues. The narrative inquiry approach emphasizes teachers' own interpretations of the classroom and validates their experience and intuition. My research 
on teachers examining their pasts as language learners falls within the narrative inquiry paradigm.

\section{Narrative Inquiry}

Clandinin \& Connelly (1991) define the narrative inquiry method as "the description and restorying of the narrative structure of educational experience" (p. 259). Narrative as a research method is modeled after the inherent quality of narrative in daily life:

If we accept that one of the basic human forms of experience of the world is as story ... and if, further, we take the view that the storied quality of experience is both unconsciously restoried in life and consciously restoried, retold, and relived through processes of reflection, then the rudiments of method are born in the phenomenon of narrative. (Clandinin \& Connelly, 1991, p. 259)

In other words, we express our past stories indirectly through the things we do in the present, as well as directly through telling them aloud. "Story" is used in the narrative method as a metaphor for life, so this means that we look to past experiences in order to understand the present; to "story" an experience is to frame it within our own meanings; and to "restory" an experience is analogous to telling a story differently a second time, from a different angle.

Narrative inquiry is seen as a natural approach to research since people think about their lives in terms of stories. In fact, stories are a basic way of processing information. Jalongo (1992) summarizes research indicating that people understand and remember information presented in story format more easily than that presented in list format. Clandinin (1992) asserts that storying 
and restorying one's personal, group or cultural story is a method of personal and social growth. Jalongo demonstrates how teaching situations can be understood through stories: the way a story is crafted about a situation reveals, to the teller and to others, insights into present phenomena such as changing situations and the ethic of caring.

The narrative method involves the elements of experience (including personal experience in studying education), time (the concept of cyclic repetition of themes in life), personal knowledge (remembering that much of a culture can be revealed in the knowledge of one person), and reflection (as an ongoing process since meaning and certainty tend to be inversely related in the study of human beings) (Clandinin \& Connelly, 1991).

Clandinin \& Connelly (1991) explain their use of narrative inquiry in studying the case of "Phil," a grade-school principal from the close-knit community of Toronto Island whose school is an innercity one in Toronto. Phil's childhood experience of community is the story behind and interacting with his current search for community for his school. Phil reflectively stories and restories his life for purposes of acting in the present. The researchers show how Phil is at once engaged in living, telling, retelling, and reliving stories and how parts of the two narratives of participant and researcher become a shared narrative through the inquiry process:

The process of narrative inquiry is characterized by movement first from experience to researcher and practitioner field notes, transcripts, documents, and mutual reconstruction of a narrative account. (pp. 268-269). 
Clandinin \& Connelly explain that when they "gave Phil's story back to him," telling him their interpretations of his practices at a staff meeting as an expression of an image of community, he began to explain his practices in terms of his early experiences of home, school, and community. Hearing his story told by the researchers caused Phil to tell the story of his past again, including new insights. This is the nature of the narrative inquiry method, within which stories generate further stories or the same story framed in a different way, and movement between the present, past and future is fluid (Clandinin \& Connelly, 1991; Clandinin, 1992; Jalongo, 1992).

The story of "Julie" is another example of the narrative method in action. Clandinin (1992) studied Julie's elementary school practice teaching. Julie had given her cooperating teacher a paper about a group of boys learning math, but it was all quotes from theory, which surprised the cooperating teacher, who expected a paper that talked about the particular boys, the particular task, and what she had learned from the experience. This gave both of them the chance to see what it was in their personal "stories" that caused the difference of expectations. The cooperating teacher was able to help Julie see how Julie's past as a learner had silenced her own voice and how her own humiliating past experiences as a child learning math had caused her to distance herself from the math the boys were doing but also had caused her to want to study peer math work. This example shows the role of the interaction between two or more people involved in the narrative approach as each redefines the stories involved. The narrative inquiry method integrates theory 
and practice since it does not take the traditional approach of applying theory to a natural phenomenon in studying it. Rather, the examples of Phil and Julie illustrate the sense that the narrative method involves "entering into the phenomena and partaking of them" (Clandinin \& Connelly, 1991, p. 260).

In his "Concluding Comments" chapter of the anthology he edited, The reflective turn: Case studies in and on educational practice (1991), Schon discusses how the contributors employ narrative inquiry in their studies of the practice of teachers and other professionals. He adds to the ideas mentioned earlier about the unpredictable turns and subtleties involved in using the narrative method (it can generate new stories and new versions of stories as well as moving easily between present, past, and future), that the method is multilayered as well. All the researchers tell "manifest stories," the surface stories of the practitioner's work. Then they may also include "metastories of research on practice," showing how their own story of doing the research interacts with that of the subject's practice. Some use "causal stories," which involve laying out temporal sequences of events in such a way as to give causal explanations of events.

Finally, "underlying stories" are the fundamental messages or arguments the author seeks to communicate through the telling of the manifest story. They are related to the author's preferred theoretical perspective. Readers can construct an underlying story from the text of a manifest one (much like practitioners' past stories can be seen in their present actions) by asking themselves why it 
might be that the manifest story includes some features and ignores others. Schon comments on his choice of the term "underlying story":

The use of 'underlying story' rather than 'assumptions' or 'framework' suggests a loosening of the bond between concept and reality. 'Story' keeps the storyteller in the picture, suggesting that different narrators might make very different things out of the 'same' reality. (1991, p. 347)

This focus on the storyteller is a manifestation of the value in reflective teaching for the person who teaches. The work of these researchers indicates that narrative inquiry is a different kind of writing for research, in which the subjects' own voices are heard and much of the writing can be in the first person, as contrasted with the traditional third-person, expository research-writing style.

\section{Journal Writing}

Personal reflection is intrinsic to the act of journal writing; therefore, teacher trainers having the goal of introducing their students to reflective teaching often give the assignment to keep a journal or do some other, similar kind of personal, reflective writing (Canning, 1991; Holly, 1989; Richert, 1992; Surbeck, Park, Moyer, 1991; Terdal \& Brown, 1995). Journal writing has many elements in common with the LLN assignment. Therefore, a review of the relevant literature is in order.

Before journal writing became an area of academic inquiry in itself, the terms "journal" and "diary" were typically used interchangeably in discussions of peoples' personal writing that focused on its literary value, cultural insights, or were personal 
accounts of how the journal benefited its author (Moffat, 1974;

Capacchione, 1989). Even Cooper, whose work is firmly within the context of reflective teaching and narrative inquiry, uses the terms "diary" and "journal" synonymously in her article, "Telling our own stories: The reading and writing of journals or diaries" (1991).

However, as journal writing expanded from strictly a personal pursuit to a topic of academic interest, the term "journal" rather than "diary" was used to refer to it, along with expanded meanings of the term "journal." Several academic fields have become interested in studying personal journals for various reasons: women's studies, history, psychology, anthropology, and education. This review addresses the increased interest in journal writing as used as a research tool within reflective education and narrative inquiry, and as such, as an object of academic inquiry in itself within reflective education.

Holly, whose book, Writing to grow: Keeping a personalprofessional journal (1989), is within the reflective teaching tradition and presents ways in which teachers can be researchers using their own journals as biographical, narrative methodology, makes explicit the difference between these two terms. She describes diaries as "a format for authors to let it all hang out" (p. 18) without worrying about what others may think of their reactions to the day's events. Many people throughout history, especially women, have kept such diaries. Some well-known examples are Anais Nin, Virginia Woolf, and May Sarton. According to Holly, diaries are useful, but are more limited in several dimensions than journals. 
Journals build upon the foundation of diaries since the expression of emotions and the premise of privacy are basic in both. Holly (1989) explains that:

Like the diary, the journal is a place to 'let it all out.' But the journal is also a place for making sense of what is out. (p. 20) Journals are more comprehensive than diaries because diaries stop with the expression of feelings, but in journals, making connections and seeing themes and patterns is also important. The author usually has some purpose in mind for keeping the journal and returns to past writings to analyze and interpret them in a way related to this purpose. In fitting with this, journals are also not time-bound: daily events can be recorded, but a journal can also "range unfettered through time to explore and connect topics and questions" (p. 20). Other works on journal writing tend to corroborate Holly's conceptualization of the term "journal": the journal is seen as aiding in some kind of personal project rather than simply being a place to record the day's events (note the wording of titles such as One to one: Self-understanding through journal writing (Baldwin, 1977) and The creative journal: The art of finding yourself (Capacchione, 1979).

In short, a journal, in contrast with a diary, is intentionally used as a tool for personal and professional growth. Holly (1989) maintains that, in the case of teachers studying their own practice through the use of a journal, it becomes a special application of the traditional research journal, which many researchers use to record their ideas, keep track of working hypotheses, and collect evidence 
(data). When a personal journal is used this way, the subject of inquiry is oneself and "evidence" can include one's subjective thoughts and feelings.

Journals are well suited to the particular aims of reflective teaching research: the keeping of journals by teachers as research tools for reflection on their practice supports the emphasis on the person who teaches. Holly (1989) and Cooper (1991) both say that the main question for a journal-writer is "Who am I?". Teachers' journal keeping also supports the valuing of the increased integration of theory and practice. In addition, the journal fits with the multilayered nature of narrative inquiry.

Holly (1989) mentions that there are various types of journalkeepers: "chroniclers," who record daily events in a diary; "travelers," who keep journals to remember certain events; "explorers"; and "pilgrims," those who attempt to discover the answers to the question, "Who am I?" This last type, those who purposely undertake an inner journey, is the most relevant to journal-keeping within reflective teaching and narrative inquiry, both as a research method and as the object itself of inquiry.

This "pilgrim" approach, with its focus on exploring and understanding oneself, is also the most similar to the purpose of the LLN assignment. Admittedly, the LLN assignment is not the same as personal journal-writing. One main difference is that the students in the Teaching English to Speakers of Other Languages (TESOL) program wrote a reflective piece on their recollections of being learners of a second or foreign language as an assignment, whereas 
literature on journal writing tends to assume that the writers are keeping a journal of their own free will. Another important difference is that the writers of the LLNs knew that their work would be read by the professor. Journal writing, on the other hand, usually is private. Also, the LLN is a one-time assignment while a journal is an ongoing process.

Nevertheless, the abundant commonalities between this selfdiscovery approach to journal writing and the LLN assignment enable work done on this type of journal-writing to serve as a background for this study. Although the LLNs are a class assignment, the choice of what language learning experience to describe and how to present it is the writer's: topics in journals are chosen freely as well. The professor's instructions for the LLN asked students to draw upon "emotional memories of particular events" and then to "reconstruct this experience." The LLNs were to be descriptive, not analytical. As Holly (1989) includes in her definition of journals (above), emotions and personal reactions are central to them.

Also, journals often include forays into the past "to explore and connect topics and questions" (Holly, 1989, p. 20). Although students are not asked to connect their past language learning experiences with their future choices as teachers at the time of writing the LLNs, since the LLNs should not include analysis, the professor does present this as a connection that could be made at a later time: her instructions read: 
When you are in your own classroom, it is likely that the choices you make as an educator are intimately connected to these experiences.

The implicit suggestion is that students will analyze the narratives at a later time, and this fits with Holly's characterization of a teacher's journal as "a book someone returns to" (p. 20) and in which, upon analysis, themes and patterns appear.

Sources on journal writing within the reflective education and narrative inquiry traditions, in addition to Holly (1989), include Cooper (1991), Richert (1992), Canning (1991), and Surbeck, Park, \& Moyer (1991). These are supported by sources on journal writing in general (Baldwin, 1977; Capacchione, 1979, 1989) that also focus on the therapeutic and self-understanding aspects of journal writing. (Both Baldwin and Capacchione are counselors who advocate the use of a personal journal in conjunction with therapy.)

These sources assert that there are numerous benefits to becoming aware of and examining one's past experiences through journal writing. (In two instances, sources from outside the field of journal writing support some of these assertions and are included as well.) The benefits of reflecting in writing on past experiences form five main themes.

One is that the process of writing about one's past experiences, particularly negative ones, can be cathartic (Holly, 1989; Capacchione, 1989; Baldwin, 1977). Unpleasant memories seem to dissipate when they are brought out into the open through writing. Holly provides quotations from two very different journals: Virginia Woolf wrote in her journal, "Now that I say it I don't feel it ... Melan- 
choly diminishes as I write" (quoted in Holly, 1989, p. 72). The second quotation on the cathartic quality of writing about difficult experiences is from a teacher who participated in her journal writing study:

It's difficult to relate all the feelings, intentions one has--only one's words are heard ... I often overstate kids' foibles (in the journal) just to let off pressure. (p. 72)

Holly also gives examples from teachers' journals in which their humorous approach to writing about stressful experiences helps them find relief and softens their outlook.

The results of two experiments by Pennebaker, a psychologist, also point to the cathartic effects of writing about traumatic experiences. In one experiment (Pennebaker, 1988), 50 undergraduates wrote for 20 minutes on four consecutive days about either "The Worst Trauma of My Life" or about superficial topics. Immediately before and after writing, the students filled out questionnaires that tapped their moods, such as depressed or guilty, and physical symptoms, such as headaches and tense muscles, and blood samples were taken from each student on the day before and on the last day of the writing exercise. Students chose to write about experiences ranging from attempted suicide to being laughed at by a stepfather to the death of a dog. There was no evidence that the writing helped right away but the blood samples taken after the fourth day showed evidence of enhanced immune response: the white cells of those who had written about traumas increased their reaction and sensitivity to "invaders" more than did those of the students assigned to write about trivial events. This continued over 
the next six weeks. Five months later the confessees had visited physicians half as often as the "superficial" writers. The students who showed the greatest improvements in health were those who wrote about events that they had refrained from telling others.

In another experiment, Pennebaker and colleagues asked 41 recently fired, middle-aged, professional men to spend 20 minutes writing for five consecutive days. Half were told to focus on the trauma of losing a job, while the others just reported their daily activities. A control group of 22 unemployed volunteers did no writing at all. Eight months later, more than half of those who had written about their job loss had found new positions, while fewer than a quarter of the diary keepers and even fewer from the non writing group had done so. All put the same amount of effort into the job search. Pennebaker explains that losing a job leaves a person feeling hurt and angry, feelings which can show in an interview unless they have been confronted and processed. He says getting one's feelings on paper helps in understanding the experience and attaining some sort of closure. Pennebaker concludes that actively confronting upsetting experiences reduces their negative effects on peoples' general physical health as well as on their social success (Willensky, 1993).

A second benefit to writing about one's past experiences (negative, positive, or neutral) in a journal is that once writers see patterns in their past, they become free to either continue these patterns of thought and behavior into the future or to change them. Journal writing helps people to see these patterns as well as make 
connections between events (Capacchione, 1979; Cooper, 1991; Holly, 1989). Past experiences seem less random. Holly says that coming to recognize these patterns is:

almost like reading about someone else ... Once we see the broader context within which we acted, our behavior makes sense. (p. 72)

Once people have sorted out various aspects of their past, these become more available to their conscious minds and they are in a better position to make choices and decisions, including possible changes (Capacchione, 1979; Holly, 1989). Hoopes (1979), writing about the psychology of intercultural communication, says that members of a culture are not conscious of their culturally conditioned perceptions of reality: as long as these are "out of awareness" (p.16), it is not possible for people to understand or change them in themselves. This idea supports the assertion of the writers on journaling who claim that a person must be aware of something to change it. Holly cites studies showing that people who have written their life stories as a class assignment frequently experience major life changes soon afterwards. However, Holly adds, the prospect of change can be threatening and so people tend to feel freer to explore their pasts when they are comfortable with their present circumstances.

Another benefit entails greater self-discovery and "finding one's voice." Cooper (1991) claims that a major benefit of writing about one's past is self-discovery through addressing the question, "Who am I?". She suggests that the answer "may be not one self, but many past selves, the people we used to be" (p.97). People can gain 
greater understanding of their current selves by travelling back into the past to find the past selves that form the present self. Holly (1989), Capacchione (1989), and Baldwin (1977) also see selfunderstanding as a reward of inquiry into one's past through a journal.

One aspect of the self-knowledge to be gained through journal-writing about one's past is "finding one's voice," according to Cooper (1991). Seeing patterns in one's past makes changing them possible, but these patterns are not always objective and so coming into one's own understanding of how they are arranged is Cooper's definition of "finding one's voice." Cooper says, "Telling our own stories is a way to impose form upon our often chaotic experiences and, in the process, to develop our own voice" (p. 97). The authors' own voices as storytellers define their lives in their journals. Discovering their own voices in this way makes people feel like powerful, active agents in their lives. Cooper discusses Belenky's concept of "constructed voices": the individual's intuitive knowledge, and society's expectations of that individual, "received knowledge," often clash, and it is the task of the individual to attain some kind of integration of the two, a "constructed voice," in order to "find a place in the culture" (Cooper, 1991, pp. 108-110).

A fourth benefit of probing one's past through journal writing is becoming aware of a certain internal dialogue between different aspects of the self, or "voices." Various theorists explain this internal dialogue, or relationship between one's own voices, through different metaphors (Holly, 1989; Baldwin, 1977; Cooper, 1991). The 
commonality is that one of the voices often takes the role another person might, such as the caretaker to the cared-for, the listener to the storyteller, and the reader to the writer. These two voices are especially suited to aiding reflection in written form, and work together to help writers probe deeply to make connections that they had not been aware of and then to analyze them. Learning to be aware of this internal dialogue makes people more self-sufficient in their personal reflections. For example, Holly points out the usefulness of this "reader's" perspective in rereading one's own journal:

Rereading a journal is like beholding a movie. When you write, it is from the actor's perspective on stage. When you reread, you are the audience: you have the benefit of moving through time, seeing the story develop over time without being caught in the action. In a sense, you are reliving the action, but with an outside observer's perspective. (p. 163) Baldwin (1977) sees the "reader" and "writer" voices involved in a person's journal-writing as a skill to be developed, where the "reader" voice serves as a point of observation of oneself.

Finally, through reflecting on their pasts in journals, people learn to value and tap their own experience in dealing with new situations. Such benefits as seeing themselves as active agents and learning to work with the two "voices" inside themselves encourage people to continue to find resources within and to exercise their greater sense of self-responsibility (Capacchione, 1989). In short, through reflecting in journals on their past, people acquire the habit of reflection (Holly, 1989). 
CHAPTER III

\section{METHODOLOGY}

\section{RESEARCHDESIGN}

\section{Setting and Subjects}

This study was conducted in a state university in a large city on the West Coast. The group of subjects consisted of all the students who agreed to participate, from an intact class taught within the Department of Applied Linguistics. The Department offers several programs of study. Two of the most popular are the undergraduatelevel Certificate in Teaching English as a Second Language (TESL) and the graduate-level M.A.-Teaching English to Speakers of Other Languages (TESOL) programs. These professional preparation programs do not offer state certification to teach in public schools, and most of their graduates intend to teach English to adults. Most of the students in the class the subjects were taken from, TESOL Methods, are enrolled in one of the above two programs. Certificate and M.A. students take most of their courses together, as they do TESOL Methods, Certificate students earning undergraduate credit for them and M.A. students earning graduate credit. Both Certificate and M.A. students study, in addition to TESOL Methods, theoretical linguistics, applied linguistics, and literature and cultural studies. Graduate students also complete a thesis. 
TESOL Methods is a three-term sequence that introduces the students to approaches, methods, and techniques of teaching English as a Second Language (ESL) and English as a Foreign Language (EFL). The first two parts of the data base for this study consisted of the language-learning narratives (LLNs) and free-writes, both assignments given in the first term of TESOL Methods, which focuses on macro-level variables and an introduction to instructional methodology. The third part of the data base, the individual interviews, took place while the students were enrolled in the second term of TESOL Methods, which emphasizes teaching techniques.

There is a practice component each term. In the second term, many students are practice teaching, so some of the students were practice teaching at the time of their interviews.

Forty students were enrolled in the first term of TESOL Methods. Of these, thirty-one gave permission for their LLNs and free-writes to be used in the study. These students ranged in age from their early twenties through their sixties. Most were in their mid-twenties to early thirties. Both native and non-native speakers of English were represented. Most (twenty-six) of the thirty-one were women. Of the eleven who volunteered to be interviewed, nine were women.

\section{Approach}

A qualitative approach was chosen because it was felt to be the most fitting to the nature of this study for three main reasons: the study regards the students' subjective feelings as valid, uses 
naturalistic data, and is exploratory. The study also includes elements of narrative inquiry methodology. This study is interested in determining how the students were affected, and whether they were helped, by examining their own pasts as language learners through the LLN assignment. Narrative inquiry guides this research because of the focus of narrative inquiry on studying the cyclic repetition of themes in life (Clandinin \& Connelly, 1991). Here, that is seen in the nature of the study's overall question regarding how themes from the TESOL students' past experiences come back to influence their current intentions as teachers, and how examining their past experiences consciously may change the role these play as the student moves into the new role of teacher.

Although the researcher's analysis regarding how the students were affected by writing the LLNs plays a large part in the study, if the subjects' own feelings on the matter were not solicited in depth, the study would have been impossible, since many of the ways the students were affected by and interacted with the assignment were not directly observable from the outside. Qualitative research is concerned with understanding human reactions from the viewpoint of the people involved, and researchers working within the qualitative paradigm believe that much of knowledge is subjective in nature (Nunan, 1992; Larsen-Freeman \& Long, 1991). Narrative inquiry philosophy is influential on this point as well. Narrative inquiry uses the concept of "stories" as a metaphor for life, believing that people look to their past experiences in order to understand the present. To "story" an experience is to frame it within a person's 
own meanings (Clandinin \& Connelly, 1991). Researchers using narrative inquiry believe that each person's way of organizing his or her own experiences, past and present, results in that person's "reality," so reality is subjective and varies from person to person (Clandinin \& Connelly, 1991; Schon, 1991). Schon explains how this idea is reflected in the term "story":

'Story' keeps the storyteller in the picture, suggesting that different narrators might make very different things out of the 'same' reality. (p. 347)

It follows that in research done within the narrative inquiry tradition, the subjects' own voices are heard extensively, and that is the case in this study, whose data base consists of the subjects' own writing as well as interviews with the subjects, and where many direct quotes are included in the body of the text.

The focus of this study is an assignment done by students in an intact class, as a class requirement. As such, the LLNs are naturalistic data. It is important to study this question naturalistically (to examine the writing that was actually done as part of a course) because, if other TESOL teacher educators were to apply the findings of the study to their work, they would be most likely to apply them in a classroom situation. Such naturalistic and uncontrolled data tend to be studied qualitatively since the unobtrusive nature of qualitative methodology does not affect the subjects' behavior as the clinical research setting does. In qualitative research, the context in which the human behavior occurs is considered important (Nunan, 1992; Larsen-Freeman \& Long, 1991). 
Although leaders in language education are beginning to focus on teacher reflection (Bartlett, 1990; Richards \& Lockhart, 1994; Wallace, 1991; Freeman \& Richards, 1993), there has been little published research on future TESOL teachers reflecting on their pasts as language learners, so this research is exploratory. A qualitative approach is well suited to such exploratory research because, as contrasted with quantitative approaches, which focus on confirming hypotheses, qualitative methods are oriented to description and discovery (Nunan, 1992; Larsen-Freeman \& Long, 1991). In this study, deriving new questions from the data could be as important a contribution as addressing the guiding questions the study started out with. In other words, some directions of this study were datadriven. Qualitative research involves:

an attempt to remain as open-minded as possible, and there is an interaction between questions and data to the extent that it is not uncommon for the questions themselves to change in the course of the research. (Nunan, p. 69)

Narrative inquiry is also often data-driven because, as subjects' frames for organizing their experiences are drawn out in their stories, the process typically leads to the generation, by the subject, the researcher, or both together, of further stories or the same story framed in a different way (Clandinin \& Connelly, 1991: Clandinin, 1992; Jalongo, 1992).

In designing this study, the strengths and weaknesses of validity and reliability in qualitative research were considered. External validity is "the extent to which the results can be generalized from samples to populations" (Nunan, 1992, p. 15). The 
use of all the narratives and free-writes from an intact class increases the external validity of the study since the findings are more likely to be generalizable to another entire TESOL class. Internal validity is "the interpretability of research" (Nunan, p.15). The naturalistic conditions of this study strengthen the internal validity because, since the two assignments were done for a real class, the study is examining how students actually experience the assignments as real classwork. Both the internal and external validity of the study were boosted by the fact that the LLNs and inclass free-writes were both done under naturalistic classroom conditions. The external validity was helped by this since the LLN and free-write portions of the research were conducted in contexts which resembled the real world contexts to which the findings would be asserted to be applicable.

Internal reliability refers to the extent to which an independent researcher, on analyzing one's data, would reach the same conclusions as the original researcher did (Nunan, 1992). External reliability refers to the extent to which a replication of one's study would yield similar results (Nunan). In qualitative research, the subjectivity of interpretation is more acceptable than in quantitative research, so reliability is less of a concern than validity. Nevertheless, it is desirable for readers to have access to the data used in making interpretations. Readers can obtain a sense of the original data from the large quantity of quotations throughout the text. Also, as much of the original data from this study as is possible 
to include in the appendix given length constraints, is available there for readers.

\section{DATA COLLECTION AND ANALYSIS PROCEDURES}

\section{Language Learning Narratives}

The first part of the data base was comprised of the language learning narratives. These were included to be examined directly since their effect as an assignment was the focus of the study. Of the students who gave permission in writing for their narratives to be used, thirty-one of these were actually included because that number corresponded to the number of free-writes whose authors had also given permission. Voluntary consent for the inclusion of the LLNs was obtained by the professor of the class when she asked students who wished for their LLNs to be included in the study, to indicate so in writing across the top of a copy of the assignment at the time of turning it in. The assignment involved writing a three to five page description of a past experience in learning a second or foreign language. The assignment was worth fifteen percent of the course grade, and was due early in the first term of TESOL Methods. The instructions in the syllabus were as follows:

Anthropologist James Spradley used the term 'right brain experience' to refer to a technique of recollection in which an individual tries to draw upon emotional memories of particular events as well as visual, auditory, and olfactory sensations. In this language learning narrative, you are asked to recollect the sights, sounds, smells, and your feelings of a language learning situation you have been in. This can be an in-class or out-of-class experience, in the U.S. or in 
another country, or a positive or a negative language learning experience. Your task is to reconstruct this experience.

To prepare for this assignment, I suggest that you sit down in a calm, quiet place without distractions. You may want to close your eyes for a bit. Try to visualize a particular setting. Who is your teacher? Where are you sitting? Who is around you? What are they wearing? What do they look like? What do they sound like? Who is saying what to whom? How do you feel? What is happening? Are there certain classroom rules you remember? Why are you in this class? Do this for between ten minutes and half an hour. Then jot down in a series of phrases, things that you want to remember.

Working from your list as a prompt, create a narrative in the present tense about a particular class or out-of-class experience. Do not analyze your situation. The purpose of this assignment is to create a body of data which you will be able to explore later.

Remember, every cell has a memory! Whether you believe it or not, you have stored away a rich tapestry of memories of previous language learning experiences. When you are in your own classroom, it is likely that the choices you make as an educator are intimately connected to these experiences.

Before analyzing the LLNs, codes were invented to represent each subject and a master list of the codes and corresponding names was made. Then copies of the LLNs were made with the names covered and the codes were written on the copies. Throughout the process of collecting and analyzing the three parts of the data, the master list was referred to only when necessary, to match up students' LLNs, free-writes, and interviews. Otherwise, the researcher saw only the codes on a regular basis.

The analysis of the LLNs was made in response to the first guiding question of the study, "What happened when the subjects 
wrote the LLNs? What did they write about?". First, all the narratives were read through, a third of them at each sitting, and themes that stood out were jotted down. Next, each narrative was read again to add second impressions to the list of themes. This list of themes was then categorized into six broad themes (Table III). Not everything that occurred in the narratives was included in these six themes, but most of it was. The rationale for organizing the content of the narratives into these six themes reflects the qualitative and narrative inquiry methodologies underlying this study in terms of the researcher's entering into the study without preconceived notions of what might be found, and in terms of letting the subjects' voices come through. This is discussed in detail in Chapter IV. After the six themes were determined, the narratives were examined again for specific examples of the various aspects of each theme. These passages were marked in the narratives and the codes of the narratives where the passages could be found were written under each theme.

Each LLN was also categorized for the language being learned, the first language of the subject, whether the experience was formal or informal, in the subject's native country (L1 country) or in the country where the target language was spoken (L2 country), whether it was an overall positive, negative, or mixed experience, and the age of the subject at the time the experience took place (Appendix A). "Formal" meant in a classroom or dealing with a professor about classroom work. "Informal" meant using the language in out-of-class experiences with native speakers, including casual discussions about 
papers, school conditions, etc. "Mixed" was chosen to characterize a narrative only if there really was some substantial degree of balance between positive and negative elements in it. The following type of narrative, of which there were several, was characterized as "negative": the gist of the story was a humiliating classroom experience which the author ended with something to the effect of "However, I thought it over and I think things will improve." These were considered negative because the "positive" ending was brief and seemed to have been added on as an afterthought to soften the impact of reading the student's negative experience.

\section{Free-writes}

The free-writes were an impromptu in-class writing assignment given by the professor in order to obtain data on the subjects' own ideas soon after writing the LLNs about how writing the LLNs had affected them. This in-class assignment was given before the LLNs were returned to the students. At the beginning of class, they were asked to write for seven minutes on the following question, which was posed orally and also written on the board:

How does writing about a past language-learning experience relate to what you may or may not do as a teacher in the future?

Students wrote one or two short paragraphs in response and thirtyone of these are included as the second part of the data base for this study. All free-writes were used with permission from their authors.

First, the free-writes were copied without the names, and the codes added, as with the narratives. I read the free-writes for the 
first time, keeping a list of the impressions I got. Next, I typed them all into a computer because the handwriting of some of them had been slowing down my reading. After this, I read them all again, adding to the list of impressions, connections, and themes.

This list was then compared with the three guiding questions for the study to see which seemed to be addressed in the data from the free-writes. The first half of the first guiding question had been answered by the data from the narratives, and the remaining questions all did seem to be addressed in the data from the freewrites. To these, another data-driven question from the narratives was added. The data from the free-writes were examined collectively to answer most of these questions. For one, however, the data corresponding to various categories of experience (positive/negative, age, etc.) were examined category by category. Next, the list of themes that had been found during the first two readings of the free-writes was examined to see which guiding questions the themes answered. Then the narratives were examined a third time, looking for specific examples of each of these themes. The examples were recorded in the same way as were those from the LLNs.

\section{Guided Interviews}

Interviews provided an opportunity to gather some of the subjects' individual, detailed perspectives on what it meant to them to revisit a language-learning experience. Volunteers were solicited from the TESOL Methods II class, where most of the students who 
had written the LLNs and free-writes were continuing on from TESOL Methods I. I described the purpose of the research in general terms as being to learn about the relationship between future EFL/ESL teachers' ideas about how they intend to teach and their TESOL Methods coursework. I did not say that the focus was the LLNs, in order not to bias their answers to questions in the interviews that would not mention the LLNs. Therefore, it was inevitable that some students who had not given permission for their LLNs and freewrites to be used, or who had not been in the previous TESOL Methods I class, would volunteer for the study. Only two did, and I called them later to simply tell them that enough subjects had been found. At that point, fourteen eligible volunteers remained on the sign-up sheet that was circulated around the classroom. The original intention was to interview ten students because that number seemed large enough to encompass a representative cross-section of the students (one-third of the LLN/free-writes subjects) yet also to be manageable. I decided not to cancel any interviews, however, so that in case any of the students did not come to their interviews, the number of interviews would not be fewer than ten. Three students did not come to their interviews and so the total number was eleven. Originally, there were six ideas for interview questions but six questions seemed to be too many. The six-question interview was tested with two of my friends who had completed the TESOL Methods sequence, and on the basis of how these friends responded to each question, some seemed more fruitful than others. Along with this criterion, the four final interview questions were selected based 
on how effective they were likely to be at soliciting information on how the experience of writing LLNs had influenced TESOL students' current thinking, and at following up on themes that had emerged from the narratives and free-writes. Only the last question fully revealed that the focus of the study was on the language-learning narratives. The text of the questions appears in Chapter IV, along with detailed explanations for why each question was chosen.

The interviews were conducted in the private conference room of a coffee shop on campus. Each interview lasted ten to fifteen minutes. Before the interviews, subjects were given two copies of the consent form. One of their signed copies was for them and the other for the researcher. Each subject was asked if it was all right to tape record the interview and told that only I would listen to the tapes or see the subsequent transcripts, that the tapes would be erased before the time of the thesis defense, and that excerpts from their interviews might appear in the thesis, but identified there only by code. All the subjects agreed for the interviews to be taperecorded. The subjects' codes, not their names, were written on the tapes and their names were not referred to again from this point on. Interviewees were told that they would be asked four questions about their teaching intentions and how these might relate to their TESOL coursework, and that each interviewee would be asked the same questions. Each question was read verbatim, and the questions were asked in the same order to each subject.

Themes that emerged in response to each question were noted for each interview. Then these themes were compared to the 
question to determine in what ways they answered the question. Next, specific examples, either paraphrased or directly quoted, were sought for each point of the answer. It was only at this point that parts of the interviews were actually transcribed word-for-word, to form the quotes that were used in the text. The details of the interviews, in addition to the findings from the LLNs and free-writes, were used to help explain the answers that emerged in response to the interview questions. 


\section{CHAPTER IV}

\section{RESULTS \\ LANGUAGE LEARNING NARRATIVES}

\section{Introduction}

Thirty-one language learning narratives (LLNs), from a firstterm TESOL Methods class, formed the first part of the data base for this study. These narratives were part of a class assignment. Students were instructed to reconstruct a language-learning experience from their past, whether in-class or out-of-class, in the United States or another country, positive or negative. Some students wrote about one particular class session that stood out in their memory while most recreated a typical class which was a composite of the various individual sessions they remembered.

The languages studied and numbers of people describing learning them were: Spanish (6), French (6), English (5), German (5), Japanese (3), Hebrew (2), and one each for Russian, Chinese, Swahili, and Arabic (Table I). The first languages of the authors of the narratives were: English (26), Japanese (2), and one each for German, Russian, and Thai (Table I). Twenty-one narratives involved formal (classroom) experiences while nine described informal (out-of-class) language-learning. All informal experiences took place in the country where the language being studied was 
spoken. The setting for sixteen of the narratives was the "L1 country" (the subject's native country), while for fourteen it was the "L2 country" (a country where the language being studied was spoken). Eleven were overall positive experiences, thirteen were overall negative experiences, and six were significantly mixed positive and negative. One narrative contrasted a formal, negative experience that took place in the L1 country with an informal, positive one that occurred in the L2 country. The vast majority (27) wrote about language-learning experiences that happened when they were adults, either traditional college-age or older. Two described high school experiences and two described childhood experiences that occurred when they were about twelve (Table II). (See Appendix A for a representation of all the characteristics of each narrative.)

Six main themes emerged from the narratives. These themes were data-driven. Each appeared very frequently in the narratives, and together, they account for most of what came up in the narratives. I chose to focus on affective variables in language learning (including the themes of characteristics of teachers who were liked, characteristics of teachers who were disliked, nervousness about speaking the second language (L2), and emotional responses to one's own perceived "successes" and "failures" in the L2), language learning strategies, and teaching approaches. Affective variables in language learning, learning strategies, and teaching approaches are all important issues to the field of second language acquisition today. In addition to the criteria of frequency and 
TABLE I

FIRST LANGUAGES (L1s) AND LANGUAGES BEING LEARNED (L2s)

\begin{tabular}{l|c|c|}
\multicolumn{1}{c}{ English } \\
\cline { 2 - 3 } Japanese & L1 & \multicolumn{1}{c}{ L2 } \\
\cline { 2 - 3 } German & 26 & 5 \\
\cline { 2 - 3 } French & 1 & 3 \\
\cline { 2 - 3 } Spanish & & 5 \\
\cline { 2 - 3 } Russian & & 6 \\
\cline { 2 - 3 } Hebrew & 1 & 1 \\
\cline { 2 - 3 } Thai & & 2 \\
\cline { 2 - 3 } Swahili & 1 & \\
\cline { 2 - 3 } Chinese & & 1 \\
\cline { 2 - 3 } Arabic & & 1 \\
\cline { 2 - 3 } & &
\end{tabular}

$\mathrm{N}=$ Number of narratives falling under this category

TABLE II

OTHER CHARACTERISTICS OF EACH NARRATIVE

\begin{tabular}{c|c|c|c|}
\cline { 2 - 3 } Formality * & $\frac{\text { Formal }}{21}$ & $\frac{\text { Informal }}{9}$ & \\
\cline { 2 - 4 } & $\frac{\text { L1 Country }}{16}$ & $\frac{\text { L2 Country }}{14}$ & \\
$\begin{array}{c}\text { Pos/Neg } \\
\text { Experience * } \\
\text { Age }\end{array}$ & $\frac{\text { Positive }}{11}$ & $\frac{\text { Negative }}{13}$ & $\frac{\text { Mixed }}{6}$ \\
\cline { 2 - 4 } & $\frac{\text { Adult }}{27}$ & $\frac{\text { High School }}{2}$ & $\frac{\text { Child }}{2}$ \\
\hline
\end{tabular}

Note. * These computations do not add up to 31 narratives because one narrative contrasted a formal, negative experience in the $\mathrm{Ll}$ country with an informal, positive experience in the $\mathrm{L} 2$ country.

$\mathrm{N}=$ Number of narratives falling under this category 
importance to second language acquisition research, principles of reflective teaching research and narrative inquiry guided my choice of these themes by serving as a reminder to let the subjects' own voices come through to define what was important to them.

There was a sense of power and urgency in the narratives when the authors were speaking about such issues as the way they felt about their teachers, their comfort level in the classroom, their anxiety over speaking in class, and the way they felt when they thought they had "succeeded" or "failed" at using the L2. Other topics were also brought up in the narratives, but these affective issues I have highlighted stood out because they were presented as important to the authors personally, as having made an impact on them, and even sometimes as having been transforming moments. Traditionally, affective variables have been overlooked in second language acquisition research, although they are currently of great interest (Shumann, 1975; Beebe, 1983; Guiora, 1972a). They are also considered important in reflective teaching research (Schon, 1983; Greene, 1986) and narrative inquiry (Schon, 1991; Clandinin \& Connelly, 1991).

The focus on affective issues in the narratives fits within this study's reflective teaching and narrative inquiry framework. Researchers focusing on reflective teaching are interested in studying teachers' affective concerns because of the orientation to studying teachers as whole persons rather than simply implementers of "technical rationality" (Schon, 1983). Getting in touch with their feelings about current events or past memories helps teachers be 
more aware of themselves as complete, multidimensional beings who draw on their affective understandings as part of the inner resources they employ, along with cognitive resources, in responding to specific classroom situations (Schon, 1983; Greene, 1986).

Narrative inquiry also supports the identification of affective issues as a strong theme in this study. Researchers using the narrative inquiry approach to studying teacher reflection begin a study of a teacher's experience with relatively open expectations and a willingness to pursue whatever the subjects may present as personally important to them. The affective issues written about in the narratives were important and meaningful to those who wrote about them: they described them in detail and there was a sense of reaching out to the reader to be understood. Narrative inquiry allows subjects to define their own stories in this way, since individuals' ways of telling their stories help to create the meaning in them (Schon, 1991; Clandinin \& Connelly, 1991).

Pennebaker's (1988) work on people writing about traumatic experiences provides another rationale for including the LLN authors' powerful (especially negative) emotions, as expressed in their narratives, as a topic of study: the results of this study could be compared with his finding that those who wrote about traumatic events from their past, experienced cathartic benefits as a result of doing so.

A further reason for the choice of affective variables as themes is that, along with language learning strategies and teaching approaches, they are an issue of interest in second language 
acquisition research. There is a great deal of research on affective variables in language learning (Shumann, 1975; Beebe, 1983; Guiora, 1972a), the identification of learning styles and strategies (Scarcella \& Oxford, 1992; Oxford, 1990; O'Malley, Russo, \& Chamot, 1983), and the benefits of various approaches to teaching foreign language (Richards \& Rodgers, 1986). The results of this qualitative study, carried out within the tradition of reflective teaching, could support aspects of second language acquisition theory, such as serving to make it more robust.

\section{Characteristics of Teachers Who Were Liked}

Thirteen of the narratives mentioned characteristics of a teacher the student liked (Table III). Teachers described positively in the narratives ranged from being mentioned in passing as ones whose personality enabled the student to relax enough to have a positive learning experience, to those who were considered truly magical and memorable. Regardless of where individual second- or foreign-language teachers were located on this continuum, certain characteristics were appreciated by their students. First, these teachers simply liked their students and showed that they wanted to be in class teaching them. This basic positive attitude was reflected in these teachers' facial expressions: they were described as having "kind eyes," "a friendly face," "a warm smile," etc. They acted glad to see the students, often greeting them personally before class and enjoying a chat with them before or after. Several students remarked directly that the teacher seemed to like them. One 
TABLE III

NUMBER OF NARRATIVES MENTIONING EACH THEME

Theme Number of Narratives

\begin{tabular}{|l|c|}
\hline $\begin{array}{l}\text { Characteristics of teachers } \\
\text { who were liked }\end{array}$ & 13 \\
\hline $\begin{array}{l}\text { Characteristics of teachers } \\
\text { who were disliked }\end{array}$ & 7 \\
\hline $\begin{array}{l}\text { Students' nervousness } \\
\text { about speaking }\end{array}$ & 19 \\
\hline $\begin{array}{l}\text { Students' emotional responses } \\
\text { to language learning experiences }\end{array}$ & 14 \\
\hline $\begin{array}{l}\text { Students' language learning } \\
\text { strategies }\end{array}$ & 12 \\
\hline $\begin{array}{l}\text { Teachers' approaches to } \\
\text { language teaching }\end{array}$ & 15 \\
\hline
\end{tabular}


student, reminiscing about a favorite German teacher, remembered singing in class in terms of the teacher's own enjoyment: "He loves to sing German folk songs with us. It's fun for us, too ..." (20). This excerpt also suggests that when teachers shared aspects of their own culture in class in this way, it was usually felt to be a sign of the teacher liking the students.

Teachers who were liked by their students were personally involved with whatever they were doing during class time, cared about the students' learning, and some truly went out of their way for the students. Several writers spoke of their teachers as being passionate not only about their teaching but about life in general. One teacher who went out of his way for the students is the above German teacher: he sometimes made German food at home for them and then brought it to class, and he carried his guitar to class, then enthusiastically told them the stories of the folk songs they sang. Another teacher started each early-morning class by giving the students cups of Turkish coffee.

Although some teachers who were liked had volatile, boisterous personalities to match their passion, most were fairly calm, even-tempered people. Words used to describe this quality included "peaceful," "relaxed," "informal," "mellow," "comfortable" and "patient." Praise and encouragement were also appreciated when given in an unexaggerated way, by a calm teacher, at appropriate times. This kind of gentle touch seemed to have a soothing effect on students anxious about their performance. One student described feeling more and more relaxed as her cheerful, gentle Spanish 
teacher proceeded through the first meeting of an intensive immersion course. At the end of this first day, some low-key praise from this teacher was also appreciated:

We each are speaking very hesitantly and as (we) are struggling through this first exercise our teacher compliments each of us on what we do well, and it seems as though we all feel better about taking such a big risk in speaking in our second language. ... I think I'm going to like this class and I will do fine. (23)

Although students liked teachers who were relaxed, they did not want their classes to be too easy. Teachers who were calm but also competent and able to provide a challenge were specifically mentioned by two people: "She is very mellow and knows her French! You could ask her anything about the grammar and she would know it." (13) and "Despite Herr (X)'s strict attention to detail, he is hardly stiff or formal" (9). Others also referred to liking competent teachers because they provided challenge and variety in their lessons, because they were fair, and because they seemed to know what their students needed. One student ended her narrative on a favorite English teacher by recalling her appreciation for this teacher's timely teaching of self-study of vocabulary through understanding prefixes and suffixes, as well as how to use an English-only dictionary, allowing her to add these things to her repertoire of learning skills when she was ready for them.

\section{Characteristics of Teachers Who Were Disliked}

Seven people described the characteristics of language teachers they had disliked (Table III). In contrast to the personalities of 
teachers who were liked, teachers students remembered disliking were generally irritable and uninspired, and three of them even acted hostile and quite angry. A number of other parallels were found in which attributes of disliked teachers were the direct opposites of characteristics attributed to those who were liked.

Whereas teachers who were liked were described in various ways as being competent, those who were disliked showed fewer signs of dedication or sensitivity to student needs. One teacher was often late to class and another was frequently unprepared. One spoke too much English (the students' first language) in class. In general, these teachers were insensitive to the way their students were experiencing the class: the pace was too fast (they were unaware that the students were all exhausted) or too slow (the students were bored); in three cases, students wrote about not knowing how they were doing, or what they were doing wrong when speaking the target language in class.

Teachers who were liked were relaxed and informal but those who were disliked were formal and rigid. One student remarked that it was hard to get used to his teacher always wearing a suit. Another described the grand entrance of her teacher into the classroom with a confident expression and rigid posture. This teacher often admonished the students to sit up straight, never smiled, and rarely engaged in small talk with them. In this class, the students' homework assignment had been to look up the pronunciation of new English words. The teacher then called on students, asking them how the words were pronunced and got angry 
when the answers were incorrect: "Even though we are only students, we are not allowed to make a mistakes in pronouncing the new vocabulary" (2). Another student had a teacher who, in discussing the results of a disappointing final exam with the student, fiercely defended each point without showing any flexibility in even acknowledging the student's point of view.

Descriptions of teachers who were disliked contrasted with the descriptions of teachers who were liked. The teachers who were liked wanted to be in class, liked the students, and cared about their learning. On the other hand, the faces of the teachers who were disliked were described as "scowling," "not smiling or laughing," and "motionless." They were uninspired, boring, and did not offer praise. Five narratives described impatient teachers. The students could often sense the teacher's hostility and irritability toward them. An example of several of these qualities is the following:

My professor does not smile or laugh. He is serious, boring, and uninterested. He does not listen to me and so I do not talk. He calls on me occasionally, but appears impatient when I speak up hesitantly. ... here I feel hostility and tension reciprocated between myself and the instructor. (22)

Three teachers went beyond irritability to anger and intimidation. The teacher who was irritated when students pronounced words incorrectly finally blew up, ordered the class into the hall, and told them they could discontinue the "optional" summer-school class if the students did not appreciate the teacher's efforts. Another volatile teacher began to shout when a student's repetition of a Spanish sentence was incorrect. This excerpt also 
illustrates the common phenomenon of students not knowing what they are doing wrong:

"No conozco a nadie en este clase," I reply in corrected form. In a loud voice, shouting much the way Francisco Franco did in old film footage I have seen, Professor Martinez says, "conozco." I reply back, "conozco." This time in an even louder voice he says, "conozco!" I'm beginning to feel as though he's trying to turn me into a parrot. Why does he keep saying that same word over and over? Am I not saying it correctly? ... Let's try it again. Maybe I will accidentally say it correctly. "Conozco." (The professor grits his teeth and stares out the window in aggravation.) ... "I still don't know what I did wrong. Nobody is talking to me. Am I not worthy of receiving feedback?

One professor was sarcastic and abusive, responding to a student with a speech impediment, "Oh, Otto, is this the best you can come up with? I thought this is a tenth grade English class. Or maybe I'm in the wrong room today" (8).

\section{Students' Nervousness about Speaking}

Fear and anxiety about speaking the second- or foreignlanguage being learned was a striking theme. Nineteen of the narratives (nearly two-thirds of the total) expressed the student's fear of speaking in front of others (Table III). Most of these descriptions were of a classroom situation, though a few were of outof-class encounters in the foreign country. Naturally, the angry kinds of teachers described above exacerbated these students' anxieties about speaking in class, but this fear was pervasive in the narratives, regardless of the particular teachers. 
Some felt discomfort simply being in the classroom. One got jittery before class, hearing classmates practice the day's oral drill. Another began to feel tense as she stepped into the room, and another when the teacher entered. Some reflected anxiously on whether their abilities would prove to be strong enough to succeed in the course. Two were concerned because they were older than the others and worried whether they could keep up. Several were nervous because of various pressures they felt: to pass the class in order to graduate, to get a good grade, to perform well on the Test of English as a Foreign Language (TOEFL), and in one case, to live up to one's own past good performance. Much of these students' success in their foreign-language classes hinged on oral performance, and so many of these pressures become associated in the students' minds with speaking in class. Even when they did not refer to pressure to succeed in the course, students expressed anxiety over speaking, because they did not want to have attention focused on them or to appear foolish.

Several of the narratives addressed this fear of speaking, but in another context: out-of-class situations in the L2 country. One person felt nervous when she was invited to a party where German would be spoken. Another was afraid to present her first full sentence to a co-worker in French. A teenager wanted to speak Hebrew with the people near her on the plane to Israel, but could not find the courage:

Those teenagers would think I'm weird if I just went up to them and asked them questions. Those ladies would probably ignore me if I told them my name and where I came from. 
What if they laugh at me? What will I do if I forget a word and use the wrong one instead? What if they make fun of my accent? (18)

Within the general fear of speaking was the fear of being called on in class. This was a common experience in the narratives, with eight people mentioning it. Several said that being called on to answer a question was frightening and that they really disliked it. A number said that they sat in class hoping fervently not to be noticed and not to be called on:

I wonder if he is going to call on me. Maybe he will stop this drill before he gets to this side of the room. ... I'm praying. I'm praying hard! Oh no. He's looking right at me. (16)

To several, the pause while the teacher chose whom to ask seemed unbearably long and tense. Students looked down or sat out of the teacher's line of vision in hopes of being overlooked. One whose teacher called on students in the order of where they were sitting counted how many girls were left before her to see whether the exercise would end before it got to her. This nervousness while waiting to see if one would be called on probably kept students from listening to and benefiting from whatever was happening in class at the time.

The fear of speaking in class often led to physical reactions of stress. Several spoke of tight, churning stomachs. Other physical reactions included blushing, feeling cold, a pounding heart, sweaty palms, a dry throat, and a shaky voice. One student experienced several physical signs of nerves while waiting in the hall for a Spanish oral examination. During the examination, this progressed 
into a self-described "panic attack": her vision blurred, the room spun, and she could not remember any Spanish.

Nervousness about speaking in class led several people to feel self-conscious about what the teacher or other students were thinking about them while they were speaking. One wondered whether his Japanese teacher's smile meant she approved or that she was trying not to laugh? Several of those who were uncomfortable speaking in class felt hostile toward those for whom it appeared easy: "Someone volunteers 'Si, hace calor,' and I feel annoyed with that person. What is she doing here if she already knows Spanish?" (7).

\section{Students' Emotional Responses to Language Learning Experiences}

In students' descriptions of their fear of speaking the L2, and in their portrayal of their teachers, it became clear that learning a language was an emotional experience for many people. Fourteen of the narratives (nearly half) addressed the authors' emotional responses to what they perceived as their own successes or failures at communication in the L2 (or at language-learning in general) (Table III).

Failures. The most powerful emotions were found in response to negative experiences that the student considered to constitute language-learning "failures." Some of these illustrated how just one negative experience could severely discourage the learner, even when it occurred following years of feeling successful in learning the particular language. The story of the teenager wanting to speak 
Hebrew to the other passengers on her plane bound to Israel continued with her unable to summon up the courage. She was not a beginner at Hebrew, having attended a Hebrew elementary school in the United States. There, she had become fluent in reading and writing Hebrew. Although her spoken Hebrew was not developed much at school, she did arrive in Israel with only successful language-learning experiences behind her. In the hotel in Tel Aviv, she saw a Rabbi sitting alone and told herself he would be a good first person with whom to speak Hebrew since Rabbis were nice:

I walk up to him. I'm so excited, this is the first time I'll get to speak to a real Israeli. I gather the nerve to speak. "At deebair Ivrite?" I say. (Do you speak Hebrew?) He looks at me, the suspense and excitement are killing me! He seems puzzled. Why won't he answer? Wait, he looks like he's going to. Yeah! "Yes." He drops his chin and closes his eyes. I walk away in utter embarrassment and for the rest of the trip I refuse to answer any questions or translate any Hebrew my dad asks of me. (18)

Another situation in which a native speaker's response in English caused great embarrassment occurred in the Frankfurt airport. When the author asked an official-looking person where the train station was, he responded in perfect English, with a mocking smile. The author felt chastised for having attempted her halting German with someone who was likely to speak English. Like the teenager in Israel, the experience discouraged her from speaking the L2, in her case for the rest of the day. In both these cases, the surface-level communication was successful in terms of the non-native speaker (NNS) understanding the proposition the native speaker (NS) had expressed in the L2, but the interaction was felt to be a failure 
because of the NS's refusal to continue it in the target language. The underlying message was felt to be "You should not be speaking my language with me," either because the NS felt the NNS's L2 ability was not needed since the NS was more competent in English than the NNS was in the L2, or because the NS felt the NNS's abilities were so low that she should not want to freely display them in public.

In addition to the teenager visiting Israel, another case of a person who had so far been successful in her language learning being discouraged by one negative experience was a student in a college French literature class. Throughout seven years of junior high, high school and college French, she had received only A's as well as awards and encouragement. In this class, though, the professor's discouraging attitude dampened her confidence, his lack of passion for the language made it sound ugly when he spoke it, and she received a final grade of $\mathrm{C}+$, all of which led her to change her major.

Other strong feelings of frustration or discouragement brought on by situations that felt like failures occurred in diverse settings. For the college student whose Spanish professor reacted angrily when he tried but could not repeat the word "conozco" to the professor's satisfaction, the experience was so distressing that he spent the rest of class wondering if it were still possible to transfer into another class and daydreaming about golf as an escape.

In another situation, a Peace Corps trainee in Kenya was having a difficult time catching on to Swahili. The daily, intensive language classes were conducted in an open-air hut ("bonda") and one day, her 
classmate, Dick, was irritating her by acting bossy. That day, she was very nervous and physically stressed because of the frustration of not understanding her teacher, Rosemary. When Rosemary asked her a question, her frustration spiraled out of control:

I look at Rosemary and ask her to repeat. I sit there listening to her. Nothing. Everyone is silent. Just then Dick starts in on me again. I've had it. In total frustration and close to tears, I yell at him, "If you're so f--.-.--- smart, you answer it." There is a moment of total quiet. I glare at Dick, stomp out my cigarette, grab my bag and stomp out of the bonda. Once outside, the tears that have been just barely contained start rolling out. ... I am shocked at my behavior. I have never done anything like this before. (6)

Another student's frustration at not understanding her teacher also provoked her to tears. She had just arrived in the United States to begin the M.A.-TESOL program. In the first class she attended, a regular linguistics class, she had a hard time understanding the professor's English and even doubted whether it was in fact English:

I look at my notebook, which is empty. Then, I start crying very quietly. The instructor's voice keeps going up and down in my ears. I do not know what language he speaks. But when I listen it carefully, it is English. It is really English. I am so dumb. I do not even understand English I studied for sixteen years. (28)

Whereas these negative experiences led to very overwhelming emotions of discouragement, frustration, and anger, languagelearning experiences that felt successful brought emotional responses as well.

Successes. When students felt their L2 communication or language-learning were successful, it could be an exciting and emotional experience. Two narratives expressed the exhilaration of 
the flip side of the Peace Corps trainee's situation, that of finding themselves able to understand what was going on in a class taught only in the L2. Early in the term of an immersion German course, a student was proud and delighted to find she was understanding:

Using only the vocabulary he has taught us to that point, he defines the new item. And I understand! I know what he is saying! I'm learning German without any English! (9)

A student on the first day of a Spanish immersion class echoed these feelings: "What a kick! Every word was in Spanish and I can understand her!"

The praise of a kind German friend during a successful telephone conversation in German caused an American student in Germany to feel thrilled and proud. The conversation was with her friend Thomas. As they talked, his encouraging comments and the success of the communication led her to reflect on how many of the elements of the conversation she would not have been able to handle just a few weeks before. When he praised her German, she felt her hands tingle. She recalled that at the end of this telephone conversation, she felt free. For another student, even a fleeting success in language-learning became a proud memory: she remembered when she gave a correct answer on the first day of her first-year Japanese class.

Ups and Downs of Language Learning. Two students wrote narratives that described both the frustration of negative experiences and the pleasant glow of successes. One student contrasted two learning situations. The first was her Japanese class in the United States, in which she stumbled through memorized 
dialogues such as one that included the phrases, "It's big, isn't it?" "Yes, it is. It's big." (31). She felt the atmosphere in that class was tense and heavy. As she walked home after each class, she thought she was not very successful. She contrasted this experience with her later natural learning of Japanese in Japan: she was sitting in her apartment with some of her students and the same words from the dialogue came up, but in that real context. The students had fondly remarked that she seemed big to them. She responded, "Yes, that's right. I am big," (31) in Japanese. They all laughed. This time, the words made her happy because she felt she was really communicating, and the situation was relaxing and fun.

In another case, an American studying in France felt successful and later unsuccessful in her language-learning, all on the same day. She had been enjoying a relaxing dinner conversing with her host family but then her confidence in her French was dashed when her host sister and her husband corrected her paper for her. They found many mistakes and called the paper "illogical." Later she reflected on the nature of language-learning as including many sudden ups and downs:

Suddenly, that overwhelming feeling of second language frustration sets in. I had such a great speaking day today and suddenly I cannot write one logical sentence in this stupid language. One day I have complete confidence that I am virtually fluent, not to mention supreme grammatically, and twenty-four hours later I have to look up every single word in the dictionary to remember if it is feminine or masculine. 


\section{Students' Language Learning Strategies}

In addition to the role of affective factors in language learning, the narratives also illustrated a cognitive dimension, language learning strategies. Twelve students recounted strategies they used for learning the foreign language (Table III). Strategies used in the classroom are referred to as "classroom survival strategies" and those used in self-study or in natural interaction with native speakers are referred to as "self-study strategies."

Classroom Survival Strategies. Several students reported strategies to avoid speaking in class, and one said he daydreamed about golf as a way to get through a stressful class. However, I will focus on the more numerous positive classroom survival strategies the TESOL students wrote about, those that served to engage learners with the language, increase their efficiency in learning, and bolster their confidence. A large part of students' self-described success in language-learning involved speaking success, as seen in the above themes. Two students reported rehearsing to themselves what they were going to say in class. Whether this strategy was directly beneficial for language acquisition is questionable. However, avoiding perceived failures in the classroom was important to the students, as shown by examples such as the student who changed her major from French because of negative experiences in her French class. One of those who rehearsed what she was going to say was a student in the first meeting of her French class. She rehearsed to herself the French for "Hello, my name is What is your 
name?" as her turn approached. Another remembered rehearsing a "core conversation" on her way to her Japanese class.

A student taking a first-year Spanish oral exam recalled in detail the mental strategies she had employed to be able to ask an imaginary visitor when he had arrived in the United States. As the professor waited, sitting across from her, she worked through a panic attack to search for possible ways to perform this task. In fighting her way out of the terror, she began by searching for one Spanish word to latch onto. When she could not remember the word for "airplane," she went on to verbs for "arrive" or "come." She was flexible about not dwelling on mental blocks but instead moving on to look for alternatives. She also took one step at a time. Once she found an appropriate verb, she tackled tense: should it be preterite or imperfect? She decided preterite, but could not think of the form, so she switched from trying to construct "When did you arrive?" to "How long have you been here?". When she had trouble with that, she returned to "When did you arrive?", and so on. In addition to searching for different ways to say things and taking one step at a time, she was able to recognize what errors she was making in her thinking and then consciously redirect her approach.

This student and others used the classroom survival strategy of "pep talks," talking to themselves for the purpose of reassuring themselves that they were doing all right and to keep trying. This student encouraged herself by noting that it was her regular teacher who would be conducting the oral exams and that would be to her benefit since she was accustomed to his accent. After the exam, on 
which she suspected she did not do very well, she comforted herself by thinking that she did the best she could and would just go on from there. Another student, recognizing that he was not in the right frame of mind for his early-morning Spanish class, said to himself:

O.K., now that I've got a few brief moments to gather myself before class starts, it's time for a little self pep talk to remind myself why I come to Spanish class four days a week at $8: 00$ in the morning. (16)

He went on to remind himself that he would need more Spanish in order to be able to teach in South America.

Self-study Strategies. The narratives provided several examples of students giving themselves pep talks outside of the classroom as well. One, doing her homework at night in Germany, encouraged herself by noting that words and structures she struggled with just a short time ago had become automatic. She also reassured herself that it was only natural to feel nervous about going to a party where only German would be spoken. The student who could not understand her professor's English upon arrival in the United States gave herself a pep talk that night in her room, telling herself that other international students faced the same problem and to be patient. When it was time for a student in France to write a paper, she sat down and told herself that she could do it because it was only one page, she was the best student in the class, and besides, she had just had three cups of coffee.

This same student used two other language-learning strategies: she recognized the native speakers she lived with as resources and asked them to proofread her paper. After they found numerous 
mistakes, she analyzed her own mistakes carefully, another strategy, and discovered a pattern: most were due to literal translation from English syntax and ways of thinking. Upon discovering this, she brainstormed ways to stop doing it.

Other strategies included one student's using context to help her understand the German being spoken by a family sitting across from her on the train. Another low-proficiency student had a similar strategy: while at her new job in France, she did not try to speak much at first, but carefully observed everything. She picked up on cultural and sociolinguistic norms this way. For example, she noticed that whenever people arrived at the workplace, they said "bonjour" and shook hands with everyone. A student of English also was very observant: she paid attention not only to native speakers' English but also to their eye contact, expressions, and body language.

Two students reported on some of their specific study techniques. One had learned from her teacher that familiarity with prefixes and suffixes could make English vocabulary study more efficient and also that it was advisable for intermediate to advanced students to learn to use an English-English dictionary to study vocabulary instead of just English-Japanese dictionaries. After learning this, the student bought an English-English dictionary and a book with information on prefixes and suffixes after class and began practicing these study strategies. Someone learning German explained her study technique of keeping a notebook of certain things: 
I kept a small notebook of grammatical rules and verb conjugations. In it $\mathrm{I}$ also was starting my own system for learning the genders of nouns. I used three kinds of highlighter pens: pink, yellow and blue. Masculine nouns were highlighted in blue, feminine in pink and the neutral in yellow. (1)

\section{Teachers' Approaches to Language Teaching}

Fifteen of the narratives (almost half) described some kind of overall language-teaching approach used by the teacher (Table III). A few others described classes with no recognizable overall approach but an eclectic variety of activities taken from different approaches. Also, many of the other narratives took place outside of the classroom or if they did take place in the classroom, the author did not focus on teaching approaches. The two most commonly described general approaches were immersion and an emphasis on culture learning in the classroom. Three or fewer descriptions also appeared for each of audiolingualism, grammar-translation, and communicative methods.

Immersion. Seven of the narratives described classes conducted entirely in the target language from the first day, even if they were beginning classes. For three of these, it was a positive experience and for the other four, it was negative. Of the positive experiences, one expressed exhilaration at understanding everything in Spanish on the first day of an immersion class. Another was mildly pleased to remember that she had learned everything in German. Other than this, though, those for whom immersion classes were pleasant experiences did not specify the immersion approach 
itself as the reason the experience was positive. What all three do have in common is that the student adored the teacher, and the teacher's personality had a calming effect on the student. The German teacher was described as having a magical, riveting style and a reassuring manner. The Spanish teacher created a fantasy character on the first day, a gypsy named Ezmerelda, and asked the students to do the same for themselves. "Ezmerelda" captivated the students by quietly telling them a story about herself. In this relaxed atmosphere, the student was able to understand her Spanish. The third teacher was an English teacher in the former Soviet Union whom the student, a thirteen-year-old girl, idolized.

The negative experiences with immersion ranged from vaguely unpleasant to traumatic. One had a somewhat unpleasant experience in a French class. She was uncomfortable with being expected to speak French all the time when she felt she was not able to say all the things she was asked to, so she spoke English during pair work sometimes when the teacher was not nearby and felt relieved when the class was over and she could speak only English again. A student of Spanish recalled reacting with anger and doubt when he realized the class was being conducted completely in Spanish:

I'm having a hard time following him as he is talking only in Spanish. You know, even at the end of first year Spanish the teacher gave all the directions in English. ... I'm only picking up on a couple of words that he's saying. Does he think that by speaking only in Spanish that I would improve quicker than if he spoke some English? What's going on? (16) 
Another student was shocked when her professor began the first day of her intensive first year Spanish class in Spanish since she had never studied a language this way before. Her response was thorough exhaustion. One student learning Swahili in Kenya as part of intensive Peace Corps training panicked because she simply could not understand the teacher. She said the immersion experience was awful for her.

Culture Learning in the Classroom. Six of the narratives mentioned culture learning as a large part of their teacher's approach. The target culture was presented in several different forms in these classrooms. None of the six narratives mentioned anything negative about culture learning in the language classroom. An American studying German in Germany appreciated her teacher's willingness to extemporaneously answer questions about aspects of the culture that students found puzzling. A student of Hebrew at a combined work/study program at a kibbutz in Israel enjoyed the adventure of class being cancelled for a week and the students being required to help farmers save the apple harvest, as the class itself was converted into a real-life cultural experience of kibbutz comradeship and cooperation. A German teacher in America was beloved for sharing his culture with the students through singing German folk songs with them and explaining the stories of the songs, bringing German food he had prepared, and showing them videos on the culture of Germany.

In this German class, there were also posters of Europe on the walls and the student liked to imagine himself there, walking along 
with his backpack. Within culture learning, imagining or pretending to be in a country where the target language is spoken was a strong theme and was popular with the writers of the narratives. As the above German teacher told the stories of German Christmas carols, the student imagined what it must have been like for Franz Gruber as he wrote "Silent Night." He pictured him walking in the snow to the church where he wrote the famous carol.

As they practiced introducing themselves in German, another student liked it that they were asked to pretend they were on a street corner in Berlin. For another, the immersion approach and assuming a Spanish name gave her the sense of pretending to be in a country where Spanish was spoken: "I really like it when I hear lots of Spanish and I can get into a different identity. I like to be Juana Elena, my name in Spanish" (23). She also enjoyed an assignment which was simply to walk through town with a partner speaking only Spanish. It was especially fun when people in a bookstore looked at her and her partner and she thought they might have be thinking they were native speakers. At one point, they started to get tired and reverted to English: "Now we are speaking English. We aren't supposed to speak English. I feel like I am in another world now. I think we should go back to the Spanish world" (23). She became so engrossed in this experience of pretending, that speaking Spanish seemed like "another world." Another student of Spanish also enjoyed a course in which students were asked to assume a Hispanic identity ("Ezmerelda's" course), though the student did not directly point to this as a reason she liked the course. 
Four of these six writers used the target-language title (i.e., Herr $\mathrm{X}$ ) or teacher's assumed cultural name when referring to the teacher in the narratives even though they did not have to and the courses were over, some of them for years. This could be an indication of lingering fondness for the activity of pretending that they were in the country, and for exposure to the foreign culture in general.

Other Approaches. Two students described classes taught using an audiolingual approach. The basic premise of audiolingualism, which is based on behaviorism, is that languages are learned successfully through many correct repetitions, especially of grammatical structures. Memorized conversations, key phrases, and many drills are typical. The particular audiolingual approach used in these students' classes was the Jorden method of Japanese. Both students agonized over the "core conversations," brief, memorized dialogues they had to recite with a partner in front of the class. They worried as much about forgetting their lines as about pronunciation and grammar. Their time in the spotlight seemed to move painfully slowly. The Jorden method also included drills in which one word is changed each time.

One student described an approach that had elements of both audiolingualism and grammar-translation. It was a high school English class in Japan. The audiolingual element was a text with key sentences and drills. The grammar-translation element was found in the teacher's assignment that students look up the pronunciations and meanings of new vocabulary before the class began each new 
chapter. Grammar-translation teaches grammar deductively and focuses on translations between the target and first language. The students in this class were nervous and stressed, not because of the grammar-translation approach per se, but because of the teacher's anger when they came to class not knowing the meanings and pronunciations of the new words. A similar experience with the implementation of the grammar-translation approach occurred in a high school English class in Germany. The students were expected to know the vocabulary from a reading selection they had read at home, and to be able to provide translations when they were called on. Again, the stress came from the teacher's strict expectations and angry reactions when the translations were not perfect. When the teacher got angry, his "trick" was to ask for a whole paragraph to be translated into German, since that was very hard for the students to do successfully.

It is interesting that no one described a class conducted using the communicative approach to language learning because this approach is the one most ascribed to in second language acquisition theory today. It should be noted, however, that a number of the classes described took place ten or more years ago, though many others took place within the last couple years. The communicative approach is based on the belief that language learning occurs best when the focus is on real communication, especially with students solving some kind of "problem" together, rather than on the technical aspects of the language itself. Only two individual activities were described which could be considered communicative. A college 
Spanish class was given the assignment to go for a walk around the town speaking only Spanish, and several classes included pair work, which is typical of the communicative approach. Most of the pair work described in the narratives was mechanical in nature (practicing set phrases they had learned), however, rather than involving real communication.

\section{IN-CLASS FREE-WRITES}

\section{Introduction}

Thirty-one free-writes, one for each of the LLNs, comprised the second part of the data base for this study. In class, students wrote one or two paragraphs on the question, "How does writing about a past language-learning experience relate to what you may or may not do as a teacher in the future?" The free-writes were examined for data that addressed certain guiding questions of this study, plus one question that arose from the analysis of the LLNs. The guiding questions of this study were:

1. What happened when the subjects wrote the LLNs? a) What did they write about? b) What was the experience of writing the LLNs like for the subjects?

2. Was it helpful to the subjects to have revisited their pasts as language learners through the LLNs? If so, how?

3. Did the different categories of experiences bring particular kinds of benefits?

The first part of the first guiding question was answered through the presentation of the themes found in the LLNs. 
The free-writes were examined collectively to answer guiding questions one and two, as well as a question generated from the analysis of the LLNs, "Did the subjects comment in the free-writes that they had written about powerful emotional experiences?". This question was asked in order to determine whether the content of the free-writes supported the highlighting of mostly affective themes in the presentation of the data in the LLNs. To answer the third guiding question, free-writes corresponding to narratives entailing the different categories of experiences (i.e., formal/informal, positive/negative, etc.) were looked at in groups (i.e., all free-writes corresponding to LLNs describing formal experiences, etc.).

\section{Emotional Experiences}

The new question that arose from the analysis of the LLNs was:

Did the subjects comment in the free-writes that they had written about powerful emotional experiences?

There were many references in the free-writes to emotional experiences the writers had discussed in the LLNs. Nineteen of the free-writes mentioned that the experiences they had described in the LLNs had involved some kind of powerful emotion(s) on their part.

Comments in the free-writes about having written about strong positive emotions in the LLNs included the following. One person wrote of becoming aware of the power of encouragement because of her own experience of being cheered on by a native speaker when she was studying in Germany. Another also spoke of the impact of encouragement, from a teacher. Another mentioned the positive, 
deep connection she felt with a Spanish speaker in Guatemala. Loss of fear in speaking the L2 was brought up, as was the emotional experience of being inspired by a teacher.

Comments regarding having written about powerful negative emotions in the LLNs included several referring to their descriptions of their own "anxiety," "inhibition," "shyness," "stress," "fear," and "intimidation" in the language classroom. One said she had described her worst language-learning experience ever in her LLN. Another said her LLN had been about a highly frustrating experience. One student explained that having explored in the LLN her fear of speaking Spanish should help prevent any more of the panic attacks she felt she had experienced in a past Spanish class. Another referred to the frustration he had expressed in the narrative over the breakdown of communication with his professor. Finally, four stated directly in the free-writes that the experience they recreated in the LLNs had been a highly emotional one.

Clearly, the free-writes did support the focus on affective themes in the LLNs: many of the free-writes contained references to the importance of the authors' emotions to the language-learning experience they described in the narratives. In addition, four students mentioned that they were surprised at the emotions that came back to them as they began to write their narratives about the experiences that had provoked the emotions. The experiences of these four are discussed in the next section. 


\section{First Guiding Question}

The part of the first guiding question that was answered in the freewrites was:

\section{What was the experience of writing the LLNs like} for the students?

Four students wrote in the free-writes that during the process of writing the LLNs, they relived the emotions they had felt during the experience they were describing. One said she felt again the anxiety of the experience (of having to recite memorized dialogues in class) as she wrote the LLN. Two people reflected in the free-writes on how it felt to revisit intensely negative classroom experiences:

When I began writing my language learning narrative, I was surprised at the emotions that came back to me. By delving back into this experience in detail, I vividly remembered a very negative experience $I$ had in a foreign language classroom. ... While I was writing, much of my anger about this situation resurfaced, and I discovered the intensity of my feelings that I worked hard to bury when I was in that class. (22)

As I thought over the experience, the emotions of what I went through that day in 1988 came back. ... My Spanish teacher's methodology and how he reacted to my mistakes had a tremendous impact upon me. I ended up changing teachers. Reliving that experience through the narrative reminds me of how influential the teacher can be in the class. (16)

Both these excerpts gave a strong sense that as they composed the LLNs, the students felt surrounded once again by emotions that had had a very strong impact when they originally experienced them in their language classrooms. A fourth person recalled that during the 
process of writing the LLN, he had been forced to remember negative emotions he had felt while living in Israel:

... I was confronted with what I had not forgotten, but intentionally blocked out - those were miserable months, months of loneliness and disorientation. (21)

While for the above students, writing the LLNs was an emotional experience as they had to take note of the past feelings that came back to them, others were surprised at how much they remembered in general. The student who lived in Israel was concerned before he began writing his LLN that he would not remember enough details since the experience he wanted to describe had taken place fifteen years ago, but along with the emotions, he also remembered many other things, such as the names of all the other students who had been in his class. Several others also said they remembered details they thought they had forgotten from the language-learning experience they described. One said she was still remembering new things about the class, after turning in her LLN. One attributed remembering so much to the writing process: "Writing drags you through the process of re-working the event in your head, to maybe bring up things that may have long been forgotten" (18). Another student commented that it was hard work to recall the details of her language-learning experience.

Two other people wrote that they found themselves engaged in analyzing and evaluating the experience as they wrote about it. One said that although the students in the TESOL class were asked not to evaluate the experience as they described it, she found that she did evaluate what caused the emotions she was describing. Another 
said, "I had to look back very closely when I was writing - and I could also stand back further and analyze more easily" (29). As she wrote, she had the sense of being simultaneously very close to the events she was describing and also able to stand back to analyze what she had described. She indicated that it was easier for her to get the necessary distance to analyze something she was writing than to do so for something she was thinking about but not writing down.

\section{Second Guiding Question}

The second guiding question was:

\section{Was it helpful to the subjects to have revisited} their pasts as language learners through the LLNs? If so, how?

The question the students were actually asked to respond to in writing the free-writes, "How does writing about a past languagelearning experience relate to what you may or may not do as a teacher in the future?," is answered here as part of the above guiding question. In the free-writes, many direct answers regarding what the students planned to do as teachers were found, but students typically interpreted the question more widely, in terms of ways in which they found the assignment to be helpful, including things related only indirectly to actions in the classroom, such as personal growth.

All the TESOL students indicated in their free-writes that writing the LLNs had somehow affected what they might do as ESL/EFL teachers. Most had definite opinions on how they felt they had been affected by the LLN assignment, both in terms of what they 
would do as teachers and in terms of how the assignment had benefited them in their general professional development. Three students did admit that they were not sure yet what impact the LLN assignment may have had on them because they had so much new information in their heads, resulting from revisiting the languagelearning experience as well as from other TESOL coursework, that they had not been able to sort it all out yet. Four main themes that emerged in the free-writes provided insights toward answering the guiding question of whether and how the LLN assignment had been helpful. These themes were personal growth; general sensitivity to learner needs; connections between the student's own experience and the kind of experience the student wants to create in future language classrooms; and evaluations of past teachers (Table IV). An analysis of these themes concludes that the assignment was helpful overall.

Seven free-writes mentioned that the LLN-writing experience was helpful in terms of benefits that could be categorized as relating to personal growth: knowing oneself better, being able to see another person's perspective, coming to terms with past experiences, etc. Two said that recalling their past learning experiences had made them more aware of their own attitudes, assumptions and predispositions regarding language-learning. Another said she came to know her own "strategies, strengths, weaknesses, and fears" (19) better. One explained that she began the TESOL Methods sequence from a "teacher's" perspective, imagining herself teaching as she absorbed information about the field, but that the LLN assignment 
TABLE IV

NUMBER OF FREE-WRITES MENTIONING EACH THEME

Number of

Theme Free-Writes

\begin{tabular}{|l|c|}
\hline Personal growth & 7 \\
\hline $\begin{array}{l}\text { General sensitivity to } \\
\text { learner needs }\end{array}$ & 11 \\
\hline $\begin{array}{l}\text { Connections between student's } \\
\text { own experience and the kind of } \\
\text { experience the student wants to } \\
\text { create in future language } \\
\text { classrooms }\end{array}$ & 22 \\
\hline Evaluations of past teachers & 10 \\
\hline
\end{tabular}


widened her perspective to include that of the learner as well: "Now, I'm looking from both perspectives as I wade through theories, models, ideas, etc." (31).

Three students indicated that the LLN assignment helped them organize their past language-learning experience in their minds and bring a sense of resolution to negative experiences. For one, fear and panic attacks were the negative experience she tried to organize and resolve through the $L L N$ assignment:

Exploring my own experiences and fears is also helping me to put my own fears into a structure where I can manage them better. This should help me avoid panic attacks in the classroom, even though by definition, a teacher is less vulnerable than a student. (19)

This comment points to the student's belief that, although teachers are "less vulnerable" than students, a person's past experiences can still potentially reappear in her future life, even if the person's role has changed from student to teacher. Another student also expressed this belief, saying that grappling with a past negative learning experience allowed her to "resolve it, put it to rest, so that it will not severely taint future teaching experiences" (18). For two students, writing the LLN resulted in the personal/professional benefit of gaining a solid foundation for learning TESOL theory: being able to relate new concepts to their own concrete experience made the new information more meaningful and easier to remember.

The second theme, expressed in eleven of the free-writes, was that students felt that through reflecting on their own pasts as language learners, they had developed sensitivity to the perspectives and needs of language learners. They thought they would be able to 
identify more directly with the perspectives of their future learners, having recently revisited their own experiences: "I also will remember what it felt like to be the student" (4), "Reminding myself about how I felt as a learner of a new language will prepare me to think about how my students must feel" (14). This sense of heightened sensitivity was not related to any particular actions that would be taken as a consequence, although the TESOL students often said that as a result of becoming more in tune with the perspective of learners, they would put a heavy emphasis on encouragement and a positive affective environment in general in their future classrooms.

Of the several free-writes mentioning a resolve to be sensitive to students' need for encouragement, one student whose English teacher seemed able to intuit her students' needs and who was very encouraging, expressed the desire to be as sensitive to her own students' needs and to remember the power of encouragement. Another, also remembering being encouraged (by a friend), said it had made her feel wonderful, the power of encouragement to language learners was the primary lesson she learned from writing the LLN. Others wanted to be aware of student comfort in terms of allowing individual students to work at their own pace and promoting a "casual atmosphere (where) the students and teacher can have fun sometimes" (2).

The third theme, connections between students' own experiences and the kinds of experiences they want to create for their own future language students, is related to the theme of 
identifying with language learners because the TESOL students seemed to identify so closely with their imagined learners that they transferred their own particular feelings about their experiences learning languages to apply to their imagined students. One saw her own fears and motivations, and those of her students, as intrinsically the same:

As I reflected on (my loss of fear in speaking my second language), it made me more aware of the needs of my students, who, of course, are in the same situation. Awareness of their fears (my fears) and their motivation (my motivation) was an excellent exercise. (23)

This was a very strong theme in the free-writes: twenty-two of the free-writes made direct associations between their own negative experiences as negative models for their future teaching (they would try to do the opposite) or between their own positive experiences as positive models (they would try to recreate the experience for their students). In all but two of these, there was an absence of any acknowledgment that the way they experienced the class (or other language-learning experience) may have been different from the way the person sitting next to them did, and that therefore, their own future learners could not be assumed to appreciate all the same methods, teacher personalities, etc. that they did. None of the free-writes stated this directly, but the recognition that often, what is positive for one learner is negative for another, was not made.

Some excerpts illustrating this phenomenon follow. One woman, recalling how pleasant, informal contact with Chinese 
speakers in Taiwan had sparked her interest in studying Chinese, wanted to use informal conversation with NSs in her future classrooms because she thought other people would respond the same way she did: "I suppose, in knowing this fact about myself, I should take this into account as other peoples' experiences too" (15). Another student said:

The most primary factor in influencing how I would teach or not teach a language class will be what I experienced as a language student. I feel we try to emulate the best of what we experience and avoid the worst. (9)

Another had fond memories of an experience of learning Spanish naturally as a guide took her through a park in Guatemala:

Because this situation was so positive, it is likely that I may wish to recreate this type of experience for my future students, for instance, taking them on a field trip ... (26)

One who had written about a negative experience also saw her past experiences as models:

... I vividly remembered a very negative experience $I$ had in a foreign language classroom. ... As a future language teacher, exploring this experience provides a role model for me of how I don't want to teach. ... Exploring more positive experiences I have had will provide me with role models of how I do want to teach. (22)

Two of the students who generally intended to follow models of classroom experiences that were positive for them and avoid doing things done in classes that were negative for them, did indicate that they recognized individual differences. One of these said, "In general, (writing the LLN) helped me to see how some learners might approach a language class" (27). Four others also specifically mentioned that individual learners had a variety of needs and 
preferences. One recognized through writing the LLN that, as a result of the negative experience she described in her LLN in which she was discouraged by a native speaker from trying out her Hebrew, she may overcompensate for this in her classes by being too overbearing in encouraging students to speak. The implication was that she now recognized that her future students had not been through her experience and may not feel that same about speaking as she did.

In writing the LLNs, three students saw a connection not between what they had experienced and how they wanted to teach, but between how they currently taught and what in their past experience had influenced it. Through recalling their past experience as learners, they recognized where they had picked up certain techniques that they currently used. No judgment was attached to the recognition of the influence from the past: these students did not indicate whether they were happy or disturbed to see the origin of things they currently practiced, nor did they mention wanting to continue on in the same way or make adjustments as a result of knowing the source and reason for some of the things they did.

The fourth theme in the free-writes involved students evaluating the teacher of the class they had described in the LLNs. Based on the content of ten of the free-writes, these students seemed to have interpreted the instructions of the LLN assignment as being to evaluate a language teacher from their past and then comment on what they liked and would use when they were teachers and what 
they did not like and would not use. For example, one student's freewrite began:

I got a chance to reflect on how the teacher taught and what I liked/did not like about her style. This gave me a chance to analyze a certain person's teaching style. Some things she did I will use, others I won't use. I see this as a rich source of information waiting to be tapped. (13)

Another student said that her LLN had been about her worst teacher ever and then listed the things he had done that she would never do. The strong focus on the teacher in these ten free-writes seemed to place responsibility for the student having a successful experience, entirely on the teacher. Actually, the instructions for the LLN assignment were to recall as many details of their own experience as they could; the focus was intended to be on the student.

Those who evaluated their teacher positively and wanted to follow the teacher's example, tended to want to emulate everything about their "good role model," in a sweeping fashion. One recounted how she had described in her LLN her adoration of her English teacher and liked everything the teacher did in class. She added in the free-write that when she became a teacher herself, "nearly all my first lessons were pure imitation of what she had done," (10) but did not indicate that this had changed. She suggested that she had had a very good role model in this teacher. Another student also intended to emulate a favorite teacher when she learned to teach:

In my case, my experience was extremely positive. If I can teach in a way at all similar to my instructor, I will be very satisfied. ... Emulating a good (great?) role model is an excellent way to learn how to do anything well. 
It should be mentioned that several students who wanted to emulate a favorite teacher did say they wanted to use "most," but not all, of what the teacher had done, yet most of those who had admired their teacher were completely accepting of everything that teacher had done in the classroom.

The above themes indicate that the LLN assignment was helpful in several different ways. It provided the TESOL students with ideas related to what they wanted to do as teachers. In general, they interpreted their past experiences and teachers as models, to either emulate if the experience had been positive for them and they had liked the teacher, or avoid if the opposite were true. The tendency was strong to make direct generalizations from one's own experience as a learner to the way other learners could be imagined to feel, though there were exceptions to this. The LLN assignment related to what the TESOL students would do as teachers by making the connection between what their past teachers did and what they would do, more direct and conscious in their minds than it had been before. The effect of this was to bring out a variety of teaching intentions, the most commonly mentioned of which was to create a positive affective environment which featured giving generous amounts of encouragement to students.

In addition to helping the TESOL students set up guidelines for what they would do as teachers, the LLN assignment was also helpful in less direct ways. One of these was that the students became aware of how influential the language teacher is in the classroom in terms of determining whether the students would have positive or 
negative experiences, as well as having a strong effect on their selfconcepts as language learners. The LLN assignment was also beneficial in prompting the students to recall facts and emotions related to the experiences they described. This will probably continue to be useful to them as these details they have remembered remain available for still further analysis. Several students also described how writing the LLNs resulted in personal growth, such as organizing and resolving their own past learning experiences and gaining the ability to absorb new theory and other information while keeping in mind both a teacher's and a learner's perspective, which may indirectly improve their effectiveness in the classroom.

\section{Third Guiding Question}

The third guiding question was:

Did the different categories of experiences bring particular kinds of benefits?

For the most part, distinct benefits from different categories of experiences did not emerge from the free-writes. In some cases, there were too few of a variable for patterns to emerge (for example, only one or two people wrote of studying a certain language). Mostly, though, the reason was that the array of kinds of benefits students felt they had received from writing the LLNs was fairly evenly distributed among different kinds of experiences.

A few particular kinds of benefits did emerge from the different categories of experiences, however. In the case of the three people studying Japanese, there was a strong emphasis on wanting to avoid for their future learners the performance anxiety they felt 
studying Japanese using the Jorden method. They felt this anxiety most intensely when they had to perform "core conversations" in front of the class, a main feature of this method. They also felt uncomfortable with the "strictness" of the teachers. These students expressed very strongly in their free-writes the desire to create a relaxed atmosphere for their students.

In the free-writes of those who had written about informal experiences, all expressed a desire to try to recreate in their future classrooms the basic elements of their positive experiences, while avoiding the conditions that they felt led them to have negative experiences. This mirrored the intentions of those who wrote about wanting to recreate positive experiences, and avoid negative ones, from their formal classroom experiences. It was interesting that it was not problematic at all for those who wrote about informal situations to associate the feelings of learners in out-of-class situations (themselves) with those of students in formal language classes (their imagined future learners). It was an easy leap in their minds from one condition to the other, and the needs of learners in the two different settings were seen as inherently the same. In the free-writes, they did not even mention that the experiences they wrote about in the LLNs were out-of-class.

A distinct benefit stood out in the free-writes of those whose experience had taken place in the country where the language they were studying was spoken. Five of these expressed emphatically the value they had discovered of positive interaction with native speakers, especially in terms of the recognition that NSs' friendliness 
had had an impact on their motivation to learn the language. Four of these experiences were informal and one was formal. For one, the kindness of his teacher kept his interest in Hebrew alive through a time of cultural adjustment that was difficult for him:

The only salvation was the friendship of my teacher. $\mathrm{He}$ was a personal door into the language and my experience of some twelve years in Israel. This is the sort of relationship I would hope to emulate with my students. (21)

A student who had spent time in Egypt and learned some Arabic informally there commented:

...Feelings toward, as well as from, the new culture may affect motivation to learn the language, i.e., Egyptians were very friendly and encouraging and became even friendlier when outsiders attempted Arabic.

Both of these demonstrate that those who had felt the impact of NS encouragement on their motivation to study the language, drew generalizations from their experience which they would probably want to recreate in their language classrooms as teachers. In terms of the age of the students at the time of the experiences described, the two free-writes corresponding to narratives that described high school experiences had an interesting common element. Both mentioned the "intimidating atmosphere" $(2,8)$ of their high school English classes and wanted to create nonthreatening atmospheres for their future classes. Although it is not possible to generalize from only two cases, especially when one took place in Japan and the other in Germany, it is possible that intimidation is within the range of tolerated teacher behaviors more often at the high school level than it is for classes of children or adults. 
INTERVIEWS

\section{Introduction}

Eleven interviews with TESOL students who wrote LLNs and free-writes formed the third part of the data base for this study. These students were enrolled in the second part of the three-part TESOL Methods sequence at the time of the interviews. The interviews were voluntary and lasted ten to fifteen minutes each. The purpose for the interviews was to gather insights on the longerterm effects of having written the LLNs, as well as to follow up on two themes that emerged from the narratives and free-writes. Each interviewee was asked the same four questions, which were read verbatim and in the same order every time. The order of the questions was designed so that the interview would begin with the focus on the LLNs being unknown to the interviewees for questions 1, 2, and 3a. The focus on the LLNs was suggested indirectly in question $3 \mathrm{~b}$ and revealed in question 4 . Following are the four questions, the purposes for asking each one, and the findings.

\section{First Question}

The first question was:

What is your approach to teaching? (Tell me a little about your philosophy, concerns, and beliefs regarding language teaching.)

The purpose of this question was to discover ways in which the experience of writing the LLNs may have influenced the TESOL students' general approach to teaching as well as how this 
assignment may have combined with other coursework and theory in influencing their current general intentions. (Some were teaching part-time at the time of the interviews, so they were discussing their actual practice, rather than intentions.) This question was openended in terms of exactly what kinds of things the subjects chose to focus on: some talked mostly about philosophy, some about methods, and others about the roles of teachers and students, etc.

The two most common answers to this question involved wanting to have a student-centered classroom (five people) and wanting to create an affective classroom environment that was comfortable for learners (four people) (Table V). For some, a student-centered classroom meant one where the teacher was not overly concerned with being "in control" and students had some say regarding what and how they wanted to learn. One liked the idea of teachers presenting the language, then acting as guides while the students discover the details on their own. She also saw a studentcentered classroom as one in which the teacher is flexible and sensitive to students' learning styles in planning the class activities. Another, who had learned English in Thailand, said:

I don't want to be a teacher like when I was in my country. I don't want to be like a controller teacher. ... I don't want to control everything in class. It's like one-way communication. Teacher is the only person who speaks, and never get like interaction or feedback or any kind of responses from students. ... I want to let my students talk and ask questions, not like in the traditional classroom. (28) 
TABLE V

\section{ANSWERS TO FIRST INTERVIEW QUESTION ("WHAT IS YOUR APPROACH TO TEACHING?")}

\begin{tabular}{|l|c|}
\multicolumn{1}{c}{ Answer } & $\begin{array}{c}\text { Number of interviewees } \\
\text { giving this answer }\end{array}$ \\
\hline Student-centered classroom & 5 \\
\hline $\begin{array}{l}\text { Comfortable affective } \\
\text { classroom environment }\end{array}$ & 4 \\
\hline $\begin{array}{l}\text { Students need to understand } \\
\text { grammar rules }\end{array}$ & 1 \\
\hline $\begin{array}{l}\text { Teacher is more than a } \\
\text { facilitator }\end{array}$ & 1 \\
\hline $\begin{array}{l}\text { Make use of what students } \\
\text { already know }\end{array}$ & 1 \\
\hline Teach practical language & 1 \\
\hline Audiolingual/communicative & \\
\hline
\end{tabular}


This also illustrates the idea that a student-centered classroom is one in which students participate a lot. One TESOL student said that he valued a student-centered classroom, but had to be careful not to let his own strong personality be the focus. Another student expressed a similar idea: "When you're in the classroom, it's the students' chance to speak, not my time to lecture about things" (13).

A comfortable affective environment was described mainly as one that was relaxed and where students would feel free to talk, laugh, ask questions, and enjoy themselves. One of the TESOL interviewees makes his hope for this kind of environment explicit to his students:

I think one of the biggest things for me ... is lowering the affective filter and making (my students) much more comfortable - to give them permission to have fun in the classroom. ... I spell that out on the first day in my syllabus, that it's OK to have fun in class, that it's OK to laugh. (20)

One of the four conceived of an affectively positive classroom as a community where there is trust and the students support each other in their learning.

Two students expressed some reservations about practices that are currently popular. One questioned that all students can understand grammar when it is presented inductively and said that as a teacher, she would want to be sure that students understood the rules. Another disagreed with the idea that students have inside them all they need to learn and that the teacher therefore is only the facilitator. She felt teachers do objectively have greater knowledge than students. Other responses regarding approaches to teaching languages included making use of schema (what students already 
know) in introducing new points and teaching language "that can actually be used" (16). Only one person responded to this question by naming methods of teaching. She said she had been most influenced by a Spanish class she had taken that had been taught using the audiolingual method, but agreed most with the communicative approach. She said that her approach was eclectic and that in addition to these two methods, she might also use suggestopedia. (Others described methods in answering this question, but did not name them specifically, except one who talked about a past teacher who had used the grammar-translation method.)

Five of the eleven interviewed mentioned influences that had led to their holding the beliefs they now did about language teaching. For all five, what was mentioned was their past experiences as language learners. Three of these five past experiences were the ones they had written about in their LLNs. The student who said her method was mainly communicative did not explain what had influenced her to embrace a communicative approach, but did explain that her use of audiolingual methods had been positively influenced by an audiolingual class she had enjoyed.

Other specific mentions of one's own past experience as a learner serving to influence one's current teaching approach included two who wanted to avoid things their teachers had done. One student, whose Spanish teacher had not taught the kind of Spanish the student thought would really be needed in Spanish-speaking countries, wanted to teach practical English language skills. Another 
wanted to give her students more of a "foundation" in grammar than she had had in her French class:

because ... that messed me up with French because I never really understood any of the grammar ... because the teacher never explicitly told us the grammar. (13)

Another, however, pointed to her Japanese teacher's positive example as inspiring her to want to provide the same experience for others:

(She) did an incredible job of teaching me, from knowing nothing about Japanese ... to being able to go to Japan and function by myself. She opened a whole new world up to me and $I$ found that beyond incredible ... and I wanted to give someone else that opportunity. (4)

She said she wanted to be an empowering teacher, as her teacher had been to her. Since no one mentioned any other influences than their past language-learning experiences, no analysis can be made of how the past experience may have interacted with other factors, such as TESOL Methods coursework, in leading to the students' present teaching approaches.

The six interviews where no sources of current beliefs were mentioned were examined next to the corresponding narratives to see if the current beliefs could possibly have originated in the language-learning experiences described in the narratives. This was done to determine if it was possible that their approaches had been influenced by their past experience and they simply had not mentioned it. In the cases of three of these, this seemed possible. A student who had had a very intimidating teacher said she thought the classroom should have a relaxed atmosphere. One whose teacher 
had taught study strategies, which had been a turning point in that student's study of English, said that teaching strategies and providing opportunities for students to experience the "Aha!" reaction were central to her approach. The third said that "Teaching is creating an atmosphere where learning can happen" (19). Her narrative had described her high level of anxiety learning Spanish, and surely such anxiety would not be part of the kind of atmosphere she would believe to be conducive to learning. Including these three interviews, the total of TESOL students whose approach was influenced by their past experiences as learners is eight. Of the six of these whose approaches were related to the same experiences they had described in their LLNs, it is not known whether it was the actual experience, writing about it, or a combination of the two, that made an impression on the student.

\section{Second Question}

The second question was:

Imagine that you are a teacher of ESL/EFL or of another language. There is a student in your class who you think is nervous about being in class and very afraid of speaking the foreign language in class. How would you deal with this situation, since you know that speaking is important to language acquisition but you want the student to feel comfortable?

In asking about fear of speaking in class, that strong theme from the LLNs was explored further to seek insights into the following questions. What would the TESOL students say they would do as teachers about a situation many of them had experienced 
themselves, as learners? Did the responses of those who had written about having felt nervous in class differ from the responses of those who had not? Did their past experiences have any bearing on what they would do? If so, did they mention these experiences specifically as a way of explaining their responses? Did other coursework seem to combine with the experience of writing the LLNs to create their current intentions regarding this situation?

All the interviewees showed concern for this situation through their answers. However, the answers of those who mentioned in their LLNs that they had gone through a similar situation as language learners were in no way different from the answers of those who did not write about being afraid of speaking as learners. Six of the interviewees had written in their LLNs about being nervous and afraid to speak as learners, and five had not. Both groups' approaches to dealing with a learner who was afraid of speaking in the classroom ranged from indirect (trying to make the whole classroom more comfortable for everyone but not speaking to the student in question) to direct (discussing the dilemma directly with the student and providing encouragement) (Table VI). Three students said they would try indirect strategies, including the following. A student who had been nervous in the classroom as a learner said he would "not put (nervous learners) on the spot" (16). The same response was given by a student who had not mentioned being nervous in the classroom in her LLN. She and others also said they would get to know the student outside of class. Three students mentioned small groups as a way to reduce students' fear of 
TABLE VI

ANSWERS TO SECOND INTERVIEW QUESTION (RE. WHAT TO DO ABOUT A NERVOUS STUDENT)

Answer

Number of interviewees

giving this answer

\begin{tabular}{|l|c|}
\hline $\begin{array}{l}\text { Try indirect strategies } \\
\text { (Such as calling on the student } \\
\text { only rarely if at all, getting to } \\
\text { know the student outside of } \\
\text { class, and using small groups.) }\end{array}$ & 3 \\
\hline $\begin{array}{l}\text { Try direct strategies } \\
\text { (Discuss the dilemma with } \\
\text { the student and provide } \\
\text { encouragement.) }\end{array}$ & 5 \\
\hline $\begin{array}{l}\text { Start with indirect strategies, } \\
\text { moving toward direct strategies }\end{array}$ & \\
\hline
\end{tabular}


speaking. Five students said they would try direct strategies. Examples of direct strategies were the following. Two students who had not mentioned being nervous as learners said they would talk to the student directly. One would ask what was wrong and another would point out to the anxious student after a success that it had not been so difficult after all. Three of those who had written about being nervous themselves said they would talk to the student directly.

Four students said they would try a variety of strategies, often moving from indirect ones to more direct ones. One, who had not written about having been nervous himself, said he would first get to know the student a bit outside of class, then ask him/her what was wrong, then give him/her easy questions. He said the successes the student would have with the easy questions, together with the personal interest he had shown to that student outside of class, would probably help to build the student's confidence. A student who had been nervous herself as a language learner said she would talk to the student and ask several kind students who were doing well in the class to befriend the student. One who had been anxious about speaking as a learner, and another who had not, each said that they would introduce discussions of language-learning experiences in their classes, where the teacher and students would share their experiences and learn from each other.

Of the six interviewees who had been nervous and afraid of speaking in the language classroom themselves, two directly pointed to their past experiences as having had some bearing on what they 
said they would do about nervous students in their future classrooms. For one, the connection was found in creating opportunities for the nervous student to speak spontaneously rather than being called on, and on avoiding negative speaking experiences for the student, things she would have wanted herself when she was learning Japanese:

Because in my past learning experience, I was very nervous to speak in front of the class, I really needed to do it gradually. I would hope that I could put the student in a situation where they're challenged to speak on their own ... I want to make sure that the ones who are really nervous don't have a negative experience, because I just closed up, basically. (31)

The other one pointed to her experience as causing her to want to show the students empathy for the challenges they were going through. She said she would share her experience when she had class discussions about the process of language learning:

I would want to deal with it by showing empathy, to say that yes, I've had this experience. ... and I would certainly share that for me, (speaking) was the hardest thing, and that I had my share of fears and panics about it ... (19)

The other four who had written in their narratives that they were nervous in the language classroom as learners did not mention so when asked this question. The answers of these four to this question were compared with their narratives to determine whether their past experiences with nervousness in the classroom could have influenced what they said they would do about the situation as teachers. For two of these, no relationship was seen. For the other two, it seemed likely that their responses had been influenced by 
their past experiences: the one who said he would not put his future students on the spot had been grilled by his Spanish professor, who became more and more upset as the student did not produce the correct pronunciation; the other, who said she simply would not call on nervous students, had had an intimidating teacher who called on students and then lost her temper when they did not know the correct answer.

No students specifically mentioned anything except their own past experience as having influenced their ideas regarding how to deal with students who are afraid to speak in class. One, however, said that she wanted to learn more about learning styles, showing that she was using some of what she had already learned about them, probably from her TESOL Methods class, in formulating her response to this question. She based her answer mainly on her own experience -- students should have opportunities to speak that are low-key so that they do not have negative experiences with speaking

-- but also said that she was aware that some of her friends had thrived on speaking in their foreign language classes, and so she felt she had to learn more about how to prepare lessons that work with different learning styles.

\section{Third Question}

When you are a teacher and situations arise in the classroom that you aren't sure how to deal with, what resources will you draw upon in responding to the situations? (after the initial responses:) Do you think that you might draw upon your own past experiences 
as a language learner to give you insights into dealing with situations that arise in your classroom?

The purpose for asking this question was to find out if the TESOL students had learned, from doing the LLN assignment, to draw on their own experiences as language learners as a resource. First, the question was posed in an open-ended way to see if they would spontaneously mention their own experience as a resource, then it was asked directly.

When this question was asked open-endedly, the most common answer was clearly that the students would turn to other teachers as a resource (Table VII). Eight of the eleven interviewees said so, and they mentioned it first if they went on to name other resources. Most said other teachers would be their primary resource. Several said they would particularly turn to more experienced teachers, for example:

I would contact my mentor -- I have a couple teachers that are mentors who I've worked with -- and I would explain the situation to them, and often they're able to give a little more insight. (4)

One said he would especially seek advice from other teachers who were experienced in working with the same first languagebackground group as he was teaching. Another said she had learned of the value of consulting with other teachers in part through the small group work in TESOL Methods.

Five people said they would turn to their students as a resource, consulting with them directly about what the students thought was needed in the particular situation. Four people mentioned books as a resource they would use. One of these said she 


\section{TABLE VII}

\section{ANSWERS TO THIRD INTERVIEW QUESTION (RE. WHAT RESOURCES THE STUDENTS WOULD DRAW UPON AS TEACHERS)}

\begin{tabular}{|l|c|}
\multicolumn{1}{c}{ Answer } & $\begin{array}{c}\text { Number of interviewees } \\
\text { giving this answer }\end{array}$ \\
\hline Other teachers & 8 \\
\hline My students & 5 \\
\hline Books & 4 \\
\hline $\begin{array}{l}\text { Reflect on own } \\
\text { past teaching }\end{array}$ & 3 \\
\hline $\begin{array}{l}\text { Information from } \\
\text { Methods class }\end{array}$ & 1 \\
\hline Administrators & 1 \\
\hline $\begin{array}{l}\text { My husband } \\
\text { all classroom problems }\end{array}$ & 1 \\
\hline $\begin{array}{l}\text { Don't know } \\
\text { Internet }\end{array}$ & 1 \\
\hline Workshops & \\
\hline
\end{tabular}


would look back to the books used in TESOL Methods specifically. Another commented that while books are an important resource, the huge volume of books on teaching English as a Second Language is problematic because it overwhelms her. Other resources mentioned, by one person each, were recalling things that were addressed during TESOL Methods classes, consulting with an administrator, consulting with a husband, going to a relevant workshop, and throwing the problem out onto the TESL-list on the Internet to see what responses she might receive. One person said, before she went on to list resources she might turn to, "First, I wonder whether I could solve (the situation)" (5), indicating some tolerance with the fact that some problems cannot be completely "solved" by the teacher. Another said she did not know what she would do when situations arose that she was not certain how to deal with: "I need to get some literature on dealing with that kind of stuff before I begin my career" (13).

Three students said that they would turn to some sort of reflection as a resource, sometimes including reflection on their own experiences as teachers. However, none specifically mentioned reflection on their experiences as language learners. One said he hoped a good number of challenging situations would arise during his student teaching so that he could draw on them later. Another said that although her range of resources had been broadened recently to include consulting with other people, her style usually is "to rely on myself and read and think about things alone" (19). 
The third said she would use her teaching journal as a resource. When she taught in Japan, she started keeping a personal diary. When she realized that a lot of what she was writing was about teaching, she made it her teaching journal, and at that time, she began organizing it the way she organized lecture notes, with the text on the right and the important points on the left so that she could find them easily. She said of her journal:

I just wrote down things that happened in and out of class. Even if I'm just going to a teachers' meeting or a workshop, writing down ideas, situations, things that come up, resources that I hear about ... (31)

She wrote in her journal every day, and she explained how she used it when problems arose:

If I have a situation that comes up that I don't know how to deal with, I can go back and say, 'OK, is there a pattern here? Has the situation occurred before? Or have I learned something from a workshop that would help me deal with this situation, has someone mentioned a book that might have some information about this, is there someone I met at a workshop who I could call?' I just try to keep it all in the teaching journal.

She was still keeping the journal at the time of the interview, recording in it things she was learning in her practice teaching.

When asked directly whether they thought they might draw upon their own past experiences as language learners to give them insights into dealing with situations that arose in the classroom when they were teachers, all the interviewees said "yes," "I hope so," or "I think so." One, a native speaker of Japanese, said:

If I teach Japanese students, I know what's difficult for them and what's easy, or what kind of examples really help them to understand the difference between $A$ and $B$. 
So, teaching Japanese students, I think I can apply my experience as a learner to the students I teach.

She added that she felt she might not be able to apply her experience as a language learner to students from language backgrounds other than Japanese. Another explained that she might picture herself back in her Japanese class as a learner in order to remember what her teacher had done in situations she was currently facing as a teacher:

I might look back and say, 'Oh, this kind of situation happened in our classroom. Maybe I should deal with the problem the way that my teacher dealt with the problem in the class'. (4)

The other nine interviewees, although they said yes to the question, did not proceed to answer the exact question that had been asked. Instead of supporting their "yes" answers by giving examples of how they might look to their past experiences as learners to help them deal with specific situations as teachers, they talked about how their experiences as learners had influenced their current perspectives as teachers in general and even subconscious ways. Three students mentioned the words "subconscious"/"unconscious" in describing how they might use their past experience. For example, one said, "It probably unconsciously influences my general philosophy" (11) and another said:

Yeah, I think I do (draw upon my past experiences as a learner), but not totally consciously" (31)

However, if an influence is not conscious, it could not be purposefully drawn upon at a time when it is needed, to solve a current, specific dilemma, which was the focus of the question they had been asked. 
In answering this question, the interviewees tended to reiterate instead the kind of influence one certain experience from the past, usually the one from the LLN, had had on them and many gave essentially the same answers they had in their free-writes to the question, "How does writing about a past language-learning experience relate to what you may or may not do as a teacher in the future?". For example, the student whose Spanish teacher had gotten angry when he did not produce the correct pronunciation of a word had written in his free-write:

My Spanish teacher's methodology and how he reacted to my mistakes had a tremendous impact upon me. ... Reliving that experience through the narrative reminds me of how influential the teacher can be in the class. (16)

In the interview, he said:

I'd look to my Spanish class. I want my classes to be much more relaxed and fun and not have people feel bad about themselves.

Others also interpreted the interview question in terms of how they would borrow certain things their past teachers had done or try to do the opposite. A Thai student responded to this interview question by saying:

When I studied grammar in my country, it was so boring, so now I want to integrate every skill into the grammar class. (28) It seemed that in their thinking about this question, they started with the influence from their past and then applied it to their teaching, whereas the intent of the question was the other way around, starting with a situation in the present and then looking back into the past to solve it. The assertion that they interpreted the 
question this way is supported by the answers of two subjects who responded to the question by saying that yes, they would draw on their past experiences -- after all, their past experiences were what had caused them to want to become teachers. It is interesting that the interviewees all interpreted the open-ended first part of this question in the way it was intended while most interpreted this second part differently, in spite of the fact that the wording of the two parts of the question was not substantially different.

\section{Fourth Question}

(After summarizing the subject's narrative experience.) (For those whose LLN was about an in-class experience:) Do you think your response was typical of the other students in that class? (For those whose LLN was about an out-of-class experience:) Do you think your response would have been typical of other people who found themselves in the same situation?

This question was designed to follow up on the finding, which emerged in the free-writes, that the TESOL students tended to want to recreate in their classrooms experiences that had been positive for them, and do the opposite of whatever the teachers of classes that were negative for them did. Because they did not usually qualify these stated intentions by saying that they realized that not all learners would respond to the experiences they described in the same way they themselves had, they appeared to be unaware of possible variations in the way the other students who were in class with them might have responded to the same situation, or variations in the way others might have felt about the out-of-class experiences 
they described. This question sought to investigate the possibility that the absence of acknowledgment of individual differences did not mean that they were not acknowledged but was simply due to the students not happening to mention them.

Most of the TESOL students answered "no" (five) or "I don't know" (three) to this question. Only three said "yes" (Table VIII). Two of those interviewed had described out-of-class experiences in their narratives, and these two both answered the question "yes." One of these, who had described being at a bus stop in the Ukraine and accepting another passenger's offer to hold her heavy bag, all the time gesturing and trying to understand Russian, said that she thought other people would have responded the same way, provided they were optimistic and trusting about human nature. The other, who had described a phone conversation in Germany during which she realized how much progress she had made, said she thought other people would have felt the same excitement she did because it is exhilarating to reach the point, in speaking a foreign language, where one can speak without concentrating on the form. The one who had written about an in-class experience who had thought her response was typical of the other students, said she knew it was because the students had discussed how they felt about their intimidating teacher.

Of the five who answered "no," two said the other students had all seemed to be feeling differently from the way they felt. One of these, who had had a negative experience in a French class, said, "No. They all seemed gung-ho" (13). Another student had the opposite 
TABLE VIII

\section{ANSWERS TO FOURTH INTERVIEW QUESTION}

("WAS YOUR RESPONSE TYPICAL?")

\begin{tabular}{|c|c|}
\multicolumn{1}{c|}{ Answer } & \multicolumn{1}{c}{$\begin{array}{c}\text { Number of interviewees } \\
\text { giving this answer }\end{array}$} \\
\hline No & 5 \\
\hline $\begin{array}{c}\text { Don't know/ } \\
\text { probably not }\end{array}$ & 3 \\
\hline Yes & 3 \\
\hline
\end{tabular}


experience: he said he had been intrinsically motivated to study German, whereas the others in his class did not enjoy school as much and had taken the course as a requirement.

The other three who answered "no" essentially said that they did not consider their response typical because they said that while some felt as they did, others did not. Two said that they knew not all students worried as much as they did about their success in language classes because they had talked about this with their friends who were in other language classes. Knowing this about their friends, they said, caused them to think that there had been other students in their classes who did not react to the classes with as much stress as they did. A Thai student who had written about the challenge of taking classes conducted in English in the United States expressed this:

Some of my friends just complained and that's it! They just let it go. But some are serious, the same as me, because they worry about their studies. So it depends on the person. (28) A student who had written about being nervous speaking in her Japanese class said that most others had had a much more relaxed approach to the class. She did comment that she felt one aspect of her experience was fairly typical of other students learning a foreign language, in spite of the fact that it had not been typical among the students in her Japanese class: that she got very tired by the end of class because of concentrating so hard throughout. She pointed to recent conversations with the ESL students she was doing her practice teaching with to support this contention: 
I think a lot of students do stress the way I did, because I see some of the students in (the ESL class) and they're so tired, and afterwards, I'll say, 'How are you doing?,' and they say, 'Oh, I'm just exhausted!'.

Three of the TESOL students answered this question, "I don't know." Saying that one does not know whether one's experience was typical seems closer to a "no" answer than a "yes" answer because part of the meaning of uncertainty is that the person believes it is possible that some of the others may have felt differently. Also, two of those who said they did not know whether their experiences had been typical went on to suggest that they probably had not and that while they were in the class, they had suspected that the other students were feeling much better than they were about the class. They both remarked, however, that it had been hard to focus on what the others may have been feeling when they were so consumed by their own distress:

I'm not sure (how the other students were reacting). I was so distraught and so caught up in myself that I really didn't even have enough time to pay attention (to how the other students might have been feeling).

The other said that it was very difficult as a learner to show her vulnerability by revealing to the rest of the class how much she did not know about Spanish, and that this self-consciousness kept her from stopping to consider how the others may have been feeling:

It's real easy to start feeling like a little kid again and like you're completely inadequate and incompetent and all of that, and when you get into that place, it's hard to have good analysis skills. (19) 
It is interesting to note that both these students seemed socially isolated in their classes.

So, only three people said they believed their responses had been typical, while the rest either believed that they had not or were at least predisposed to recognizing that the others in their class may have felt differently than they had. Although the two out-of-class experiences had both been positive and both these people had answered "yes" to this question, among the "no" and "I don't know" answers, the variable of whether the experience they had written about had been positive or negative did not seem to be related to whether a "no" or an "I don't know" answer was given or to the reason for the answer.

If most of the interviewees had answered "yes" to this question, saying they believed their responses had been typical, then the intentions they expressed in the free-writes (to recreate experiences that had been positive for them and do the opposite of experiences that had been negative for them) would have seemed a logical extension of their beliefs about learners' feelings. Since most of the interviewees thought that the others did not necessarily feel the same as they did, however, the apparent contradiction arises of why people who say they recognize that a variety of learner responses existed in their past language-learning experience, would plan their future classes without taking that into account. 


\section{CHAPTER V}

\section{CONCLUSION}

\section{DISCUSSION}

\section{Introduction}

The guiding questions of the study provide structure to the discussion of the conclusions. The guiding questions were:

1. What happened when the subjects wrote the LLNs?

a. What did they write about?

b. What was the experience of writing the LLNs like for the subjects?

2. Was it helpful to the subjects to have revisited their pasts as language learners through the LLNs? If so, how?

3. Did the different categories of experiences bring particular kinds of benefits?

The second question, regarding whether the assignment was helpful and in what ways, was the main question of the study, and therefore, the most attention is focused on it here. Also, the first and third questions were largely answered in Chapter IV, but they reappear here with some concluding comments.

\section{First Guiding Question}

The first guiding question was: 
What happened when the subjects wrote the LLNs? a) What did they write about? b) What was the experience of writing the LLNs like for the subjects?

The students wrote about their memories of learning a foreign or second language. The narratives described a variety of different languages studied. About two-thirds of the narratives were about classroom experiences; the rest were about out-of-class learning. About half took place in a foreign country and half in the student's native country. Eleven were overall positive experiences, thirteen were overall negative experiences, and six were significantly mixed. Almost all wrote about experiences that had happened when they were adults.

Most of the themes that stood out and appeared frequently in the narratives were related to the students' emotions. These included discussions of the characteristics of teachers they had liked and disliked, their nervousness about speaking the language they were learning and especially about being called on by the teacher, and their emotional responses to their own perceived successes and failures with the languages they were learning. In addition to these affective variables, the two additional important themes were language-learning strategies they had used and approaches to language teaching they had experienced as learners.

The free-writes best addressed the question of how the students experienced the actual writing of the LLNs. The process of writing the narratives brought back many details of the experiences the students described, more than some had thought possible before 
they began. For several, writing the narratives was an emotional experience since the emotions of (especially negative) experiences came back again. Some students analyzed their situation even as they were writing about it, and several commented that doing this analysis (whether during or after writing), combined with confronting the negative emotions that had come back, resulted in the catharsis of resolving and putting to rest the negative experiences. Coming up with a "moral" or "lesson" from a bad experience seemed to be soothing to the students as well, in giving them the sense that it had not all been for nothing, but had actually helped them by teaching them something. It is clear that this learning which was based on personal experience was meaningful to the subjects, fitting with Dewey's (1916) contention that when people learn through their own experience, as opposed to information being given to them, it is more personally meaningful.

\section{Second Guiding Question}

The second guiding question was:

Was it helpful to the subjects to have revisited their pasts as language learners through the LLNs? If so, how?

The LLN assignment was helpful to the subjects in three main ways. There were mixed results in two additional areas. First, the three ways in which writing the LLNs was beneficial to the TESOL students are discussed. These are the following:

a) The recollection of the emotions and facts of the languagelearning experience described. 
b) Recognition of how influential the teacher is in the language classroom.

c) Recognition that their past experiences as language learners had influenced their present intentions as preservice teachers. The subjects' experience of recalling many of the facts and emotions of the scenes they described was discussed above, as was the benefit of catharsis that several felt as a result of confronting and working through negative memories. The students' recollections of the details of their language-learning experiences were also valuable because these facts and emotions became available for them to use in any continuing analyses and reflections. Also, consciously recalling the details of their experiences as language learners led many of the students to be more aware than before of their own attitudes and preferences related to language learning; that is, to know themselves better as language learners.

A second major benefit the TESOL students received from writing the LLN assignment was the recognition of how influential the teacher is in the language classroom. There was a strong focus on the teachers in the LLNs: although the directions for the assignment asked them to concentrate on their own experience, many wrote primarily about the teachers they remembered. Some discussed teachers they had liked; others, teachers they had disliked. Many expressed their fear of being called on by the teacher. Some commented on their teachers' approaches to language teaching.

Based on their own experiences from the LLNs, several commented directly in the free-writes on their realization that the 
teacher is very influential. One said that students are more vulnerable than teachers in the classroom. The free-writes showed that the way the TESOL students' teachers had seemed to feel about them was closely related to their feelings about themselves as language learners. If the teacher approved of their efforts, they felt good about themselves; if the teacher was angry or impatient with them, they quickly began to doubt their abilities. The narratives and free-writes showed awareness of this power imbalance between students and teachers. Because of this power imbalance and student vulnerability, students felt responsible to be careful about how they used their influence. One student said in her free-write that she thought of her future learners as being "in my care" (4).

Perhaps it was out of desire to decrease the power imbalance in the classroom that the most common answer to the first interview question, "What is your approach to teaching?," was the stated intention to create a "student-centered" classroom. Through their elaborations on this, it seemed that the TESOL students conceptualized a student-centered classroom as being one in which the teacher was not overly concerned with being in control and was flexible and sensitive to students' needs.

A third and very important way in which the LLN assignment was beneficial to the TESOL students was in leading them to recognize that their past experiences as language learners had influenced their present intentions as preservice teachers. Kagan (1992) says preservice teachers need to be aware of what their present beliefs about teaching are, and how the past has influenced 
them, in order to be open to assimilating new information about teaching. In their responses to two of the interview questions, several students spontaneously said that their answers had been influenced by their own past experiences as learners. Five out of eleven students interviewed mentioned that influences from their pasts as language learners had contributed to their approaches to teaching. Of the six students who were interviewed who had been nervous in the language classroom as learners, two offered these experiences as rationale for their responses regarding how they would approach the situation of having a student who was afraid of speaking the foreign language in class.

In fact, not only did the TESOL students recognize that their past experiences as language learners had influenced their present intentions, but they usually set up their past experiences and teachers as models, to either emulate if the experience had been positive for them and they had liked the teacher, or avoid if the opposite was true. There was a strong tendency to make direct generalizations from one's own experience as a learner to the way other learners could be imagined to feel, though there were exceptions to this. Many of the TESOL students, by making generalizations from their own experience and preferences to what they planned to do as teachers, did not seem to take into account individual differences by stating that they were aware that learners' needs vary. This is discussed in more detail later. Also, in modeling their teaching intentions on their own past experiences, they did not seem to include new information being learned in the TESOL 
program, or new ideas of their own which were unrelated to their pasts, in these intentions.

Perhaps this is not problematic, however. The motivation behind wanting to recreate good experiences and avoid bad ones for one's own students is generous and demonstrates identification with and sensitivity to the learners' perspective. The importance of emotion in the TESOL students' experiences may have helped to inspire them to be sensitive to providing their learners with positive experiences.

In addition, the all-or-nothing borrowing from past experience could represent one stage in an evolution in these students' understanding of how to refer to several resources in creating effective teaching plans to fit different learners and situations. As they continue in the TESOL Methods sequence, they will learn more about different learning styles. They will also have more time to process the theory they have been learning and maybe then, they will be able to start to apply it to their own lives both in terms of understanding their past experiences and planning for future classes. The probability that their ideas will continue to evolve is supported by the students who mentioned in their free-writes and interviews that they had so much new information in their heads now that it was hard to sort out.

Even if the TESOL students are not yet adept at recognizing that different students and situations require varied approaches, beginning their teaching careers with some ideas of how they want to approach teaching that are based on their own past experience 
will probably prove to be beneficial to the TESOL students. Most of the ideas they had, such as giving encouragement and explaining the process of language-learning, would be effective with most students and as such, they provide a solid starting point from which to explore the variety and subtlety of student needs.

In addition to the above, there were two areas in which the results were mixed in the sense that the benefits the TESOL students received from writing the LLNs were limited in certain ways. These were the following.

a) It is unclear whether the TESOL students became fully aware, as a result of writing the LLNs, that other people may have reacted differently than they did to the experiences they described. Whether or not they had any awareness of this, their teaching intentions did not reflect it.

b) The TESOL students did not seem able to visualize themselves, when they have become practicing teachers, using reflection on their past experiences as language learners as a resource to help them understand current situations. The fourth interview question, regarding whether the TESOL students felt their responses had been typical of other people in the same situation, was designed to follow up on the finding that the TESOL students tended to want to recreate experiences in their classrooms that had been positive for them, and do the opposite of whatever the teachers of classes that had been negative for them had done. Because they did not usually qualify these stated intentions by saying that they realized that not all learners would 
respond to the experiences they described in the same way they themselves had, they appeared to be unaware of possible variations in the way the other students who were in class with them might have responded to the same situation, or variations in the way others might have felt about the out-of-class experiences they described. This question of typicality of response sought to investigate the possibility that the absence of acknowledgment of individual differences did not mean that they were not acknowledged but was simply due to the students not happening to mention them.

Only three interviewees said they believed their responses had been typical, while the rest either believed that they had not been or were at least open to the possibility that the others in their class may have felt differently than they had. If most of the interviewees had answered "yes" to this question, saying they believed their responses had been typical, then the intentions they expressed in the freewrites (to recreate experiences that had been positive for them and do the opposite of experiences that had been negative for them) would have seemed a logical extension of their beliefs about learners' feelings. Since most of the interviewees thought that the others did not necessarily feel the same as they did, however, the apparent contradiction arises of why people who say they recognize that a variety of learner responses existed in their past language-learning experience, would plan their future classes without taking that into account.

A possible explanation is that they may have been considering for the first time how others in the class had felt when they were 
asked about it in the interview. If this were true, perhaps if they had been asked after the interviews how they planned to use insights from their own experiences in formulating their future intentions, their responses would then have taken into consideration learner variables. The possibility of a subject's growing and changing during the course of the investigation is an important part of narrative inquiry methodology, and is not seen as problematic. Researchers working within narrative inquiry believe that knowledge is built as people "tell their stories," then the researcher "gives them back their story" as he or she understands it (as I did when I summarized each interviewee's LLN experience before asking this question), at which time the subject responds with a modified version of the original story (Clandinin \& Connelly, 1991; Clandinin, 1992).

Also, human beings do not depend on logic alone when they make decisions. The TESOL students relied heavily on their own strong emotions, coming from the way they had felt about their language learning experiences, in considering their future teaching intentions. The strength of these emotions helped them in some ways, such as becoming able to identify with the learner, but may have blinded them in others. For example, it is possible that the force of their emotions blocked them from bringing in other insights as they wrote their free-writes on the question of how writing about their past experiences as learners may have influenced what they may do as teachers. 
Kagan (1992) reported that teachers-in-training tended to retain their initial beliefs about teaching throughout their teacher education programs, regardless of new information learned in the programs. They also tended to assume that their students would have learning styles and interests like their own. This would help to explain the finding of this study that the TESOL students tended to assume that their future learners would experience language classroom events in the same way they had, in spite of the fact that the TESOL Methods course they were enrolled in taught explicitly about the reality of different learning styles. Without awareness of what their past influences were, however, there would be even less chance of the students changing their perceptions. The challenge seems to be how to get the students beyond the stage of awareness of the origin of their views, to also become capable of changing their views when appropriate.

Although most of the interviewees did say during the interviews that they recognized that their experiences may not have been representative, what is most important to this study is what they learned as part of doing the assignment, and the interviews were not part of their coursework. It remains unclear whether, in the course of thinking about and writing the LLNs and free-writes, the students considered the question of whether or not other people had experienced the language-learning situations they described in the same way they themselves had. Even if the students did consider this point as they did the assignment, any awareness of variables in learning preferences and styles was not strong enough to 
be represented in their teaching intentions as they expressed them in the free-writes and interviews.

A second area with mixed results is that of what the TESOL students seemed to have learned about teacher reflection as a result of doing the LLN assignment. From their answers to the interview questions, it seemed that they were not able to visualize themselves, as teachers, turning to reflection on their pasts as language learners as a resource, though at the same time, they did demonstrate a willingness to engage in reflection.

One goal of the professor who gave the LLN assignment was for the students to become reflective teachers in general, and to learn to see their past experiences as language learners as an ongoing resource to use in that reflection, a resource that could be mined for insights into particular teaching challenges that arise.

The TESOL students tended to view the reflection that was part of the process of writing the LLNs as an opportunity to recognize how their past language-learning experiences had influenced their general approaches to teaching. In response to the first interview question, regarding teaching approaches, half of those interviewed spontaneously mentioned the role their past experiences had played in developing their beliefs. This awareness of the influence of the past probably resulted from the reflection they did for the LLN assignment. To a lesser extent, the students also pointed to the influence of their past experiences in answering the second interview question, regarding dealing with a student who was nervous. For many, the reflection they did in writing the LLNs caused them to 
recall the details of emotional experiences where they had been very nervous in class. A third of the interviewees who had written of such experiences said that their own experience had influenced how they intended to respond to a student in a similar situation.

It is very important and useful for the subjects, as preservice teachers, to have come to recognize in this way how their past learning experiences have affected their current intentions and also what aspects of these experiences they want to borrow when they are teachers, and what aspects they want to avoid. However, the kind of reflection they did for the LLN assignment was different in two respects from the kind of reflection teachers would be most likely to use on the job. First, it was because of an assignment that they engaged in this reflection, whereas any reflection teachers would do would come from their own initiative. Second, teacher reflection would probably be brought on by a particular need. The teacher would start with a practical problem in the classroom and then turn to past experience to see what turned up that might be relevant to the problem. This fits with Dewey's definition of reflection as beginning with a state of doubt or hesitation which initiates thinking, and an act of inquiring to find information that will resolve the doubt (MacKinnon, 1992). Schon (1983) sees such inquiry in practice as very important, since it is the basis for the development of professional knowledge. However, in the LLN assignment, the students started instead with the past experiences which were to serve as the source of information they could use in 
reflecting, and then applied them to current issues such as developing a teaching approach, dealing with a nervous student, etc.

The purpose for asking the third interview question was to gain insight into whether the TESOL students had learned, from doing the LLN assignment, to draw on their own experiences as language learners as a resource at times when they, as teachers, were unsure of how to proceed. In response to the first part of this question, "When you are a teacher and situations arise in the classroom that you aren't sure how to deal with, what resources will you draw upon in responding to the situations?," many solid resources were mentioned, but none of the students said they would turn to their own language-learning experiences as a resource. Three students did mention other kinds of reflection. Two of these said they would reflect on their own past experiences as teachers, in one case with the help of a teaching journal. In addition to this, one also said he would think back to his TESOL Methods course to see if a similar situation had been discussed in class and another said she would "read and think about (the situation) alone" (19).

The second part of this question, asked after the initial responses were given, was "Do you think that you might draw upon your own past experiences as a language learner to give you insights into dealing with situations that arise in your classroom?". All the subjects responded that they thought they might do so. However, only two of the eleven interviewees went on to answer in a way that demonstrated understanding of the intended meaning of the question. The question asked whether, when faced with a particular 
teaching dilemma, the subjects would look back to their own experience for insights into the situation. Instead, they talked about how their experiences as learners had influenced their current perspectives as teachers in general and even subconscious ways. The experience they tended to discuss here was usually the same one they had written about in the LLN.

All the interviewees interpreted the open-ended first part of this question in the way it was intended while this was not so for the second part. The wording of the two parts of the question was not substantially different, and in both parts it indicated that past experiences were being asked about in relation to a specific teaching situation. Therefore, I do not think the answers to the second part can be explained by saying that the subjects misunderstood it.

I think that they initially understood the second part of the question but subsequently were not aware that their replies were not actually answering it, and the reason for this was that they could not think in terms of using their own experiences as learners as a resource per se, in the way they had just been asked about. So they unconsciously shifted the meaning of the question to something that did resonate with their conceptualizations of ways they might use their insights into their past experiences. The lack of spontaneous mention in the first part of the question of considering one's past experiences as a language learner to be a resource supports this interpretation, as does the response of one student to the first part of the question. She said she did not know what she would do when situations arose that she was not certain how to deal with: "I need to 
get some literature on dealing with that kind of stuff before I begin my career" (13). It seemed that the students could not generalize the kind of reflection they had done in the LLNs, in which they started with the experience and applied it to their present general approach to teaching, to the kind they would be more likely to use as teachers, in which they would start with a problem and then search their minds for areas of knowledge and experience on which they could reflect to gain insights into the problem. Perhaps with this second type of reflection, they would have been more likely to incorporate new information they had learned from the TESOL program into their approaches since, if they learned to start with a problem and then search their minds reflectively, information from their pasts, together with theory, would probably come together to address the problem.

Also, because the students' responses to the second part of this question mentioned only the same experiences they had written about in their LLNs, there was a sense that they expected only certain aspects from their pasts as learners, the ones they had already identified in the LLNs, to be useful. They did not seem to think in terms of the possibility of searching their minds for whatever past experiences best matched a current dilemma.

Although reflection on their pasts as language learners did not seem to be an ability the TESOL students knew how to use outside of the LLN assignment, this study indicates that they were willing to reflect. They did it in the LLN assignment and all said in the freewrites that it had been beneficial, indicating that they perceived the 
exercise as meaningful and valued the process of reflection they had gone through in order to derive their individual benefits from the assignment. Also, although the TESOL students' elaborations of their responses to the second part of the third interview question showed that they did not understand how reflection might actually be manifested in their routines as teachers, it is important that they initially answered the question "yes," indicating a general willingness to engage in reflection.

\section{Third Guiding Question}

The third guiding question was:

\section{Did the different categories of experiences bring particular kinds of benefits?}

The one category of experience that brought a benefit not found in other categories was that of learning the L2 in a country where it was spoken. People who wrote about this in their LLNs said in their free-writes that it had made them aware of the effect positive interaction with native speakers had on their motivation to learn the language. They either said or implied that they would like to draw on this realization by providing chances for their future students to interact with native speakers.

Other interesting realizations were made by those who had had certain categories of experiences, but they did not constitute benefits per se of having written about these categories of experiences. (See Chapter IV, pages 90-92, for details of these.) Although the TESOL students benefited in several ways from writing the LLNs, the 
benefits did not seem to be correlated with the type of experience, except for those who learned the L2 in the country where it was spoken. Also, some categories of experience (learners of certain languages, experiences that took place when the learner was an adolescent, etc.) had too few members for any patterns to emerge in terms of benefits from having written about them.

\section{LIMITATIONS OF THE STUDY \\ AND SUGGESTIONS FOR FURTHER RESEARCH}

This research relied on information provided by a group of thirty-one subjects. While many interesting insights were found in exploring this group's experiences with the LLN assignment, the generalizability of the study was limited by its small size. For example, a large number of the subjects wrote about languagelearning experiences that were negative. It could be that this was due to some characteristic of this particular population and would not be found to such a great degree in other groups. If the study were repeated with other groups and the results compared with those of this study, it could be better determined how common negative language-learning experiences are among TESOL Methods students. Another way in which the small number of subjects was a limitation was that there were too few examples of some of the categories of experiences to see patterns within these categories. For example, with greater numbers of native speakers of each language studied, language-related generalizations could be made. One such generalization may be that reflection plays a different role in the 
lives of people from cultures that value group membership more than individualism, such as Japan. So, for example, if there had been more subjects whose first language was Japanese, it might have been possible to determine such cross-cultural differences. Again, repeating the study with a different population would address this limitation.

A second limitation of the study was that it was not always clear, when subjects pointed to influences coming from their past language-learning experiences, whether the source of the influence was writing about the experience per se or simply the experience itself. That is, theoretically, they may have mentioned these influential language-learning experiences even if they had not written the LLNs. To test this, research could be done in which the group of subjects is divided in half. Half write LLNs and the other half do not, and the researcher then asks all the subjects about their teaching intentions, beliefs, etc., to see whether those of the first group are more closely tied to their past experiences than are those of the second group (whose past language-learning experiences could be elicited after asking them about their teaching intentions).

There were a few minor problematic issues in the way the data were collected and analyzed. In designing the interview questions, it was assumed that the language-learning experiences the subjects had written about in the LLNs were among the ones that had had the most impact on them, simply because it seemed typical of human nature that people would select an experience that stood out as personally meaningful to write about. However, while the students 
were usually passionate about the experiences they described, it is not possible to know whether they described the experiences that had been most meaningful to them or whether the experiences were randomly selected because they were the first ones that came to mind. Perhaps the directions for the LLNs should have included something to the effect of, "You might be asked to refer back to this narrative in the future, so write about an experience that had an impact on you." Also, it is possible that there was some bias involved in the students' responses to the free-write question (regarding how they thought writing the LLN may have related to what they might do as teachers) because it was their professor who had posed the question to them and they may have felt pressure to demonstrate that they could see a connection and to please the professor by saying that the assignment had been helpful, which every student did say. Interestingly, though, many subjects did not hesitate to reveal to the professor various personal vulnerabilities related to the experiences they described in the LLNs.

During the interviews, I could have followed up better on the responses to the question, "Do you think that you might draw upon your own past experiences as a language learner to give you insights into dealing with situations that arise in your classroom?". The fact that the responses did not address the actual question that had been asked led to important insights. Nevertheless, if I had realized as I was conducting the interviews that the responses were not answering the intended question, I would have continued asking the 
question, with some clarifications, until the answers demonstrated understanding of the question as it was intended.

Since the results of this study showed that the TESOL students did not generalize from one kind of reflection to another, future research might study an assignment in which the reflection that was called for was the same kind as that teachers would be most likely to use in practice, that is, reflection in which a person begins with a present difficulty and then looks to his or her past experiences for insights to address the difficulty at hand. Such research could attempt to determine whether this made a difference in how likely subjects were to later say spontaneously that they would turn to reflection on their past learning experiences as a resource in dealing with particular problems.

Future research could also compare the results of this study with those of a study that looked at the language learning experiences of people who did not go on to seek careers in teaching, or even of those who had dropped out of language learning. This would help determine whether the experiences of those who later decide to become teachers are different in some way from those of other learners. If they did turn out to be different, this would be important for future TESOL teachers to keep in mind.

Finally, future research could follow up on the findings of this study by studying this same group of subjects as they become teachers, to see what changes occur in the way they make use of their past experiences as language learners. 


\section{IMPLICATIONS FOR TESOL TEACHER EDUCATION}

This study set out to explore several aspects of the effectiveness of the LLN assignment, with the study's main question being whether it was helpful to the students to have revisited their pasts as language learners through the LLNs. It was concluded that the assignment was helpful to the students in several ways: they recalled facts and emotions related to their past experiences, they noted how influential the teacher is in the language classroom and increased their sensitivity to the learner's perspective, they recognized that their pasts as language learners had affected their current attitudes and intentions, and they expressed a willingness to use reflection as teachers. Therefore, doing the LLN assignment was worth the students' effort in terms of the benefits they achieved as a result of it, and it is recommended that other TESOL programs adopt the LLN assignment as well. Teachers of TESOL Methods courses should take note that the LLN assignment seemed especially well suited to serving as a catalyst for the acquisition of intangible benefits such as sensitivity to the learner's perspective and willingness to use reflection, which can be challenging to teach since they are created less through cognitive understanding than through affective, personal conviction.

It is interesting to note that, in spite of the frequently-stated intention by the TESOL students in this study to create a studentcentered classroom, many of them focused their narratives on describing and commenting on the teacher of the class they were 
recalling, rather than focusing on their own experience. In doing this, many of them seemed not to look at their own responsibility for the success or failure of their classroom language-learning experience, but instead credited a good experience to a "good" teacher and placed the responsibility for a bad experience on a "bad" teacher. It may be that most of the students did not consider the role of their own responsibility in their past language learning because of the wording of the assignment, which suggested that the students visualize the setting and then as the first example, suggested that they visualize who their teacher was. The heavy focus on the teacher may also be attributed to the fact that the emphasis in TESOL on student-centered learning is quite recent. Perhaps the students, then, were able to conceive of it in the abstract when stating their future intentions, but not apply it to their own concrete experience to discover their own role in their language learning. Therefore, it is suggested that TESOL teacher educators discuss the issue of learner responsibility with their TESOL Methods students, either before or after they write their LLNs.

The overall significance of the study lies in the fact that a study of future ESL/EFL teachers revisiting their pasts as language learners has not been done before. As such, this study provides a body of literature on what happens when TESOL Methods students write about and reflect on their past language-learning experiences. It is the hope of the researcher that this area of research will continue to be studied. Since this was an exploratory study of teachers-intraining, it is as yet unknown whether and how asking TESOL 
Methods students to do the LLN assignment may impact their actual classroom behavior. As mentioned earlier, a study of these same subjects once they are classroom teachers would be of interest.

The following suggestions are made as ideas for improving the assignment in the two areas in which mixed results were found. Through the process of writing the LLNs and free-writes, the subjects did not demonstrably realize that other students may not have felt the same way as they did about the experiences they described. When they were asked directly in the interviews whether they felt their reactions had been typical, however, most said they did not think they had. This may have meant that they were thinking about it for the first time when they were asked. This supports the idea of having the professor ask the students explicitly, after they have written the LLNs, to consider whether other people may have experienced the class (or other language-learning situation) differently than they had, and to think about implications this may have for their teaching intentions. They seemed to need a push from outside to stimulate their thinking in this area.

Also, more group sharing of experiences would help the students to become aware of the considerable variety that exists in learning styles and preferences. Two and a half years ago, after I turned in my own LLN in TESOL Methods, we discussed our LLNs in small groups. My own narrative had been about a positive experience where I felt competent as a learner and enjoyed being part of the classroom community of learners. In the small group, it was a shock initially to hear that several others had had negative 
experiences. It was difficult for me to accept, though I think I came to accept it after I spent some time thinking about it and talking with others after class. Perhaps the students in this study felt similar resistance to understanding reactions which were very different from their own. Increased group sharing of experiences may help TESOL students confront and assimilate this reality.

Finally, since the results of this study showed that the TESOL students did not generalize from one kind of reflection to another, TESOL Methods professors may want to include assignments whose structure is more similar to the kind of reflection that teachers would be most likely to use in practice, that is, reflection in which a person begins with a present difficulty and then looks to his or her past experiences for insights to address the difficulty at hand. The kind of reflection the students did seem to master, starting with their past and then applying insights from it to their overall present teaching approach, is very valuable as well. Perhaps this latter kind, found in the LLN assignment, could be introduced first and then, when the students had recalled a number of facts and emotions, they could practice the other kind of reflection by doing assignments or writing journal entries in which an imaginary "teaching problem" was given and the students were to use reflection to come up with insights to address it. The insights could come from their past learning experiences, as well as from any other sources, such as secondlanguage acquisition theory.

Overall, the TESOL students in this study demonstrated that reflecting on their pasts as language learners was a valuable 
experience in their professional development. Therefore, with the adjustments suggested, the LLN assignment could be expected to empower other TESOL students to an even greater degree, to understand their past language-learning experiences as well as to see them as a resource once they become practicing teachers. 


\section{REFERENCES}

Baldwin, C. (1977). One to one: Self-understanding through journal writing. New York: M. Evans \& Company.

Bartlett, L. (1990). Teacher development through reflective teaching. In J.C. Richards \& D. Nunan (Eds.), Second language teacher education (pp. 202-214). Cambridge: Cambridge University Press.

Beebe, L. (1983). Risk-taking and the language learner. In H. Seliger, \& M. Long (Eds.), Classroom oriented research in second language acquisition (pp. 39-66). Rowley, MA: Newbury House Publishers.

Canning, C. (1991). What teachers say about reflection. Educational Leadership, 48, 18-21.

Capacchione, L. (1979). The creative journal: The art of finding yourself. Chicago: The Swallow Press, Inc.

Capacchione, L. (1989). The creative journal for children. Boston \& Shaftesbury: Shambhala Publications.

Carr, W. (Ed.). (1989). Quality in teaching: Arguments for a reflective profession. New York: The Palmer Press.

Clandinin, D.J. (1989). Developing rhythm in teaching: The narrative study of a beginning teacher's personal practical knowledge of classrooms. Curriculum Inquiry, 19, 121-141.

Clandinin, D.J., \& Connelly, F. (1991). Narrative and story in practice and research. In D. Schon (Ed.), The reflective turn: Case studies in and on educational practice (pp. 258-281). New York: Teachers College Press. 
Clandinin, D.J. (1992). Narrative and story in teacher education. In T. Russell, \& H. Munby (Eds.), Teachers and teaching: From classroom to reflection (pp. 124-137). London: The Falmer Press.

Cole, A. (1990). Personal theories of teaching: Development in the formative years. Alberta Journal of Educational Research, $\underline{36}$, 203-222.

Cooper, J.E. (1991). Telling our own stories: The reading and writing of journals or diaries. In C. Witherell, \& N. Noddings (Eds.), Stories lives tell: Narrative and dialogue in education (pp. 96-112). New York: Teachers College Press.

Deighton, L.C. (Editor-in-chief). (1971). The Encyclopedia of education (Vol. 3). New York: Macmillan.

Dewey, J. (1916). Democracy and Education. New York: Macmillan.

Freeman, D., \& Richards, J.C. (1993). Conceptions of teaching and the education of second language teachers. TESOL Quarterly, 27(2), 193-216.

Greene, M. (1986). Perspectives and imperatives: Reflection and passion in teaching. Journal of Curriculum and Supervision, 2(1), 68-81.

Guiora, A., Beit-Hallami, B., Brannon, R., Dull, C., \& Scovel, T. (1972a). The effects of experimentally induced changes in ego states on pronunciation ability in second language: An exploratory study. Comprehensive Psychiatry, 13, 421-428.

Holly, M.L. (1989). Writing to grow: Keeping a personalprofessional journal. Portsmouth, New Hampshire: Heinemann.

Hoopes, D. (1979). Intercultural communication concepts and the psychology of intercultural experience. In M. Pusch (Ed.), Multicultural education: A cross-cultural training approach (pp. 10-38). Yarmouth, Maine: Intercultural Press. 
Jalongo, M.R. (1992). Teachers' stories: Our ways of knowing. Educational Leadership, 49, 68-73.

Kagan, D.M. (1992). Professional growth among preservice and beginning teachers. Review of Educational Research, 62, 129-169.

Larsen-Freeman, D., \& Long, M. (1991). An introduction to second language acquisition research. London: Longman.

MacKinnon, A., \& Erickson, G. (1992). The roles of reflective practice and foundational disciplines in teacher education. In T. Russell, \& H. Munby (Eds.), Teachers and teaching: From classroom to reflection (pp. 192-210). London: The Falmer Press.

Mantle-Bromley, C. (1992). Preparing students for meaningful culture learning. Foreign Language Annals, 25, 117-127.

Millies, P. (1992). The relationship between a teacher's life and teaching. In W.H. Schubert, \& W.C. Ayers (Eds.), Teacher lore: Learning from our own experience (pp. 25-42). New York: Longman.

Moffat, M.J., \& Painter, C. (Eds.). (1974). Revelations: Diaries of women. New York: Random.

Mohlman Sparks-Langer, G., \& Berstein Colton, A. (1991). Synthesis of research on teachers' reflective thinking. Educational Leadership, $\underline{48}$, 37-44.

Nunan, D. (1992). Research methods in language learning. Cambridge: Cambridge University Press.

O'Malley, J., Russo, R., \& Chamot, A. (1983). A review of the literature on learning strategies in the acquisition of English as a second language: The potential for research applications. Rosslyn, VA: InterAmerica Research Associates.

Oxford, R. (1990). Language learning strategies: What every teacher should know. New York: Newbury House Publishers. 
Pennebaker, J. (1988). Disclosure of traumas and immune function: Health implications for psychotherapy. Journal of Consulting and Clinical Psychology, 56, 239-245.

Porter, P., Goldstein, L., Leatherman, J., \& Conrad, S. (1990). An ongoing dialogue: Learning logs for teacher preparation. In J. Richard, \& D. Nunan (Eds.), Second language teacher education (pp. 227-240). Cambridge: Cambridge University Press.

Richards, J.C., \& Lockhart, C. (1994). Reflective teaching in second language classrooms. Cambridge: Cambridge University Press.

Richards, J.C., \& Rodgers, T.S. (1986). Approaches and methods in language teaching: A description and analysis. Cambridge: Cambridge University Press.

Richert, A. (1992). The content of student teachers' reflections within different structures for facilitating the reflective process. In T. Russell, \& H. Munby (Eds.), Teachers and teaching: From classroom to reflection (pp. 171-191). London: The Falmer Press.

Scarcella, R. \& Oxford, R. (1992). The tapestry of language learning: The individual in the communicative classroom. Boston: Heinle \& Heinle Publishers.

Schon, D. (Ed.). (1991). The reflective turn: Case studies in and on educational practice. New York: Teachers College Press.

Schon, D. (1983). The reflective practitioner: How professionals think and act. New York: Basic Books.

Schubert, W.H. (1991). Teacher lore: A basis for understanding praxis. In C. Witherell \& N. Noddings (Eds.), Stories lives tell: Narrative and dialogue in education (pp. 207-233). New York: Teachers College Press.

Schumann, J. (1975). Affective factors and the problem of age in second language acquisition. Language Learning, 25, 209-235.

Smyth, J. (1989). Developing and sustaining critical reflection in teacher education. Journal of Teacher Education, 40(2), 2-9. 
Surbeck, E., Park, E., Moyer, J. (1991). Assessing reflective responses in journals. Educational Leadership, 48, 25-27.

Terdal, M., \& Brown, K. (in press). Through the looking glass: Pre-service teacher reflections on prior language learning experiences. CATESOL Journal.

Wallace, M. (1991). Training foreign language teachers: A reflective approach. Cambridge: Cambridge University Press.

Willensky, D. (1993). Writing off the unemployment blues. American Health, 12, 35 . 
APPENDIX A

CHARACTERISTICS OF EACH NARRATIVE 


\section{CHARACTERISTICS OF EACH NARRATIVE}

\begin{tabular}{|c|c|c|}
\hline \begin{tabular}{ll}
1 & \multicolumn{1}{c}{ German } \\
2 & (English) \\
3 & Formal \\
4 & L2 country \\
5 & Positive \\
6 & Adult
\end{tabular} & \begin{tabular}{ll}
1 & \multicolumn{5}{|c}{ English } \\
2 & (Japanese) \\
3 & Formal \\
4 & Ll country \\
5 & Positive \\
6 & Adult
\end{tabular} & \begin{tabular}{ll} 
& \multicolumn{1}{c}{} \\
1 & German \\
2 & (English) \\
3 & Formal \\
4 & Ll country \\
5 & Positive \\
6 & Adult
\end{tabular} \\
\hline \begin{tabular}{ll} 
& \multicolumn{2}{c}{} \\
1 & English \\
2 & (Japanese) \\
3 & Formal \\
4 & Ll country \\
5 & Negative \\
6 & High school
\end{tabular} & \begin{tabular}{ll} 
& \multicolumn{6}{c}{$\underline{6}$} \\
1 & Swahili \\
2 & (English) \\
3 & Formal \\
4 & L2 country \\
5 & Negative \\
6 & Adult
\end{tabular} & $\begin{array}{ll}1 & \underline{10} \\
1 & \text { English } \\
2 & \text { (Russian) } \\
3 & \text { Formal } \\
4 & \text { Ll country } \\
5 & \text { Positive } \\
6 & \text { Child (12) }\end{array}$ \\
\hline \begin{tabular}{ll} 
& \multicolumn{3}{|}{} \\
1 & Spanish \\
2 & (English) \\
3 & Formal \\
4 & Ll country \\
5 & Positive \\
6 & Adult
\end{tabular} & \begin{tabular}{ll} 
& \multicolumn{1}{l}{} \\
1 & Spanish \\
2 & (English) \\
3 & Formal \\
4 & Ll country \\
5 & Negative \\
6 & Adult
\end{tabular} & $\begin{array}{l}1 \quad \text { Russian } \\
2 \text { (English) } \\
3 \text { Informal } \\
4 \text { L2 country } \\
5 \text { Positive } \\
6 \text { Adult }\end{array}$ \\
\hline \begin{tabular}{ll} 
& \multicolumn{4}{|c}{} \\
1 & Japanese \\
2 & (English) \\
3 & Formal \\
4 & Ll country \\
5 & Mixed \\
6 & Adult
\end{tabular} & \begin{tabular}{ll} 
& \multicolumn{1}{c}{8} \\
1 & English \\
2 & (German) \\
3 & Formal \\
4 & Ll country \\
5 & Negative \\
6 & High school
\end{tabular} & \begin{tabular}{ll}
1 & \multicolumn{12}{c}{} \\
1 & German \\
2 & (English) \\
3 & Informal \\
4 & L2 country \\
5 & Positive \\
6 & Adult
\end{tabular} \\
\hline
\end{tabular}

Note. $1=$ The language the subject studied, $2=$ The subject's first language, $3=$ Whether the experience was formal (in-class) or informal (out-of-class), $4=$ Whether the experience took place in the $\mathrm{L} 1$ country (native country) or L2 (a country where the language the subject studied is spoken), $5=$ Whether the experience was positive, negative, or mixed, $6=$ The subject's age at the time of the experience. 


\section{CHARACTERISTICS OF EACH NARRATIVE}

\begin{tabular}{|c|c|c|c|}
\hline $\begin{array}{ll} & 13 \\
1 & \text { French } \\
2 & \text { (English) } \\
3 & \text { Formal } \\
4 & \text { Ll country } \\
5 & \text { Mixed } \\
6 & \text { Adult } \\
& :\end{array}$ & \begin{tabular}{ll} 
& \multicolumn{18}{l}{} \\
1 & Hebrew \\
2 & (English) \\
3 & Informal \\
4 & L2 country \\
5 & Negative \\
6 & Child (12)
\end{tabular} & $\begin{array}{ll}1 & \underline{23} \\
1 & \text { Spanish } \\
2 & \text { (English) } \\
3 & \text { Formal } \\
4 & \text { Ll country } \\
5 & \text { Positive } \\
6 & \text { Adult }\end{array}$ & 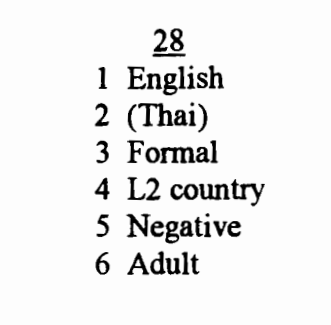 \\
\hline \begin{tabular}{ll}
1 & \multicolumn{1}{c}{14} \\
2 & German \\
2 & English) \\
3 & Informal \\
4 & L2 country \\
5 & Negative \\
6 & Adult
\end{tabular} & $\begin{array}{ll}1 & \underline{19} \\
1 & \text { Spanish } \\
2 & \text { (English) } \\
3 & \text { Formal } \\
4 & \text { Ll country } \\
5 & \text { Negative } \\
6 & \text { Adult }\end{array}$ & $\begin{array}{ll}1 & \underline{24} \\
2 & \text { Arabic } \\
2 & \text { English) } \\
3 & \text { Informal } \\
4 & \text { L2 country } \\
5 & \text { Mixed } \\
6 & \text { Adult }\end{array}$ & \begin{tabular}{ll} 
& \multicolumn{2}{c}{$\underline{29}$} \\
1 & French \\
2 & (English) \\
3 & Informal \\
4 & L2 country \\
5 & Mixed \\
6 & Aduit
\end{tabular} \\
\hline \begin{tabular}{ll}
1 & \multicolumn{1}{c}{15} \\
1 & Chinese \\
2 & (English) \\
3 & Informal \\
4 & L2 country \\
5 & Positive \\
6 & Adult
\end{tabular} & \begin{tabular}{ll}
1 & \multicolumn{20}{c}{} \\
1 & German \\
2 & (English) \\
3 & Formal \\
4 & Ll country \\
5 & Positive \\
6 & Adult
\end{tabular} & $\begin{array}{ll}1 & 25 \\
1 & \text { French } \\
2 & \text { (English) } \\
3 & \text { Informal } \\
4 & \text { L2 country } \\
5 & \text { Mixed } \\
6 & \text { Adult }\end{array}$ & 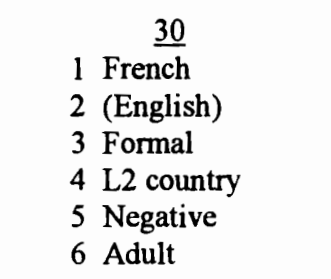 \\
\hline \begin{tabular}{ll}
1 & \multicolumn{1}{c}{$\frac{16}{1}$} \\
2 & Spanish \\
3 & English) \\
3 & Formal \\
4 & Ll country \\
5 & Negative \\
6 & Adult
\end{tabular} & \begin{tabular}{ll} 
& \multicolumn{2}{|l}{1} \\
1 & Hebrew \\
2 & (English) \\
3 & Formal \\
4 & L2 country \\
5 & Mixed \\
6 & Adult
\end{tabular} & $\begin{array}{ll}1 & \underline{26} \\
1 & \text { Spanish } \\
2 & \text { (English) } \\
3 & \text { Informal } \\
4 & \text { L2 country } \\
5 & \text { Positive } \\
6 & \text { Adult }\end{array}$ & $\begin{array}{l}1 \text { J1 } \\
1 \text { Japanese } \\
2 \text { (English) } \\
\text { 3Formal Informal } \\
4 \mathrm{~L} 1 \text { country L2 country } \\
5 \text { Negative Positive } \\
6 \text { Adult }\end{array}$ \\
\hline \begin{tabular}{ll} 
& \multicolumn{1}{c}{$\frac{17}{1}$} \\
1 & French \\
2 & (English) \\
3 & Formal \\
4 & Ll country \\
5 & Negative \\
6 & Adult
\end{tabular} & \begin{tabular}{ll} 
& \multicolumn{22}{c}{} \\
1 & French \\
2 & (English) \\
3 & Formal \\
4 & Ll country \\
5 & Negative \\
6 & Adult
\end{tabular} & $\begin{array}{ll} & 27 \\
1 & \text { Japanese } \\
2 & \text { (English) } \\
3 & \text { Formal } \\
4 & \text { Ll country } \\
5 & \text { Negative } \\
6 & \text { Adult }\end{array}$ & \\
\hline
\end{tabular}

